(Read 3 November 1897.)

\title{
SUPPLEMENTARY EXPERIMENTS UPON PROPELLER VENTILATING FANS.
}

By Mr. WILLIAM GEORge WALKeR, of London.

Since the reading of the paper on this subject at the Spring Meeting of the Institution, the author has carried out some further experiments on Propeller Ventilating Fans.

Fans with different numbers of Blades.-These experiments were made with fans of six, three, and two blades, Figs. 46 to 48 , Plate 90. Each fan was 24 inches diameter; and the blades were all flat and set at an angle of $30^{\circ}$ to the plane of rotation, and were all exactly alike in shape and area for each fan. The fans were driven at 600 revolutions per minute by belt from a shunt-wound motor. The six-bladed fan was tried first; and then its alternate blades were removed without altering the position of the fan or the angles of the remaining three blades, which was easily done by unscrewing the blades from the boss; afterwards the two-bladed fan was tried. The six-bladed fan discharged 2,350 cubic feet of air per minute, while the three and two-bladed discharged 2,535 and 2,140 respectively; their respective volumetric efficiencies were 62 and 67 and 57 per cent. These experiments show that in the fans of 24 inches diameter little or no advantage can be gained by increasing the number of blades; also that the mechanical efficiency of the three-bladed fan is the highest, the motor taking less current and the fan propelling more air than with either of the other two. The number of blades which gives maximum efficiency is probably governed by their width or area of surface; that is, the efficiency of the six-bladed fan might have been higher with smaller blade area and therefore with narrower blades. On this point reference may be made to the author's former experiments on screw-propeller surface (Proceedings 1892, page 514), which were 
carried out with screw-propellers $38 \frac{1}{2}$ inches diameter; a two-bladed screw was first tried, and was then divided into two parts forming a. four-bladed screw with blodes at right angles and having exactly the same pitch and aggregate area as the two-bladed; with the four blades. a very slight increase in efficiency was obtained, of only about $1 \frac{1}{2}$ per cent. A three-bladed screw of the same diameter was also divided into six blades at equal angles, and only a slight increase was obtained; at tho lowest speeds no gain in efficiency resulted from multiplying the number of blades. In larger fans the author has. found that the number of blades may be advantageously increased.

Experiments with Helical Blades.-All the fans previously mentioned in this paper have blades with their leading and following. edges in the same plane. Consequently the piteh throughout this plane is not uniform, but varies from a maximum at the tips of the blades to a minimum at their roots. The variation in the axial discharge of the air, as shown in Fig. 35, Plate 87, might therefore have been expected to be due to the varying pitch. Practically however the same variation in discharge was obtained with helical blades, that is with blades of uniform pitch. The 24-inch helical fan tried, which is shown in Figs. 49 and 50, Plate 91, was made with a uniform pitch of 3 feet, so that the angle of the tips is about $27^{\circ}$ to the plane of rotation. The helical blades were carefully made from sheet brass. 1-16th inch thick, and the true helical surface was cut on a wooden block, to which the blades were pressed until their surface coincided with that of the block. The fan was run at 600 revolutions per minute. Anemometer readings were taken at a distance of 18 inches in front of the fan. In Fig. 54, Plate 92, is shown the velocity of the air in feet per minute at the different points indicated. No delivery tube was employed, the fan being entirely open in front as well as behind; the conditions were thus the same as in the former trial described in page 453. The maximum axial velocity was 1,340 feet per minute at a radius of 5 inches, and the minimum velocity 230 feet at 12 inches radius. A great similarity will be noticed between Figs. 54 and 35, showing that the helical form of blade has not rendered the velocity of discharge more uniform than it is with flat blades. 
The rotary velocity of the air was also measured at the same distance in front of the fan, by placing the face of the anemometer in the same plane as the axis of the fan. In Fig. 55, Plate 92, is shown the rotary velocity at different radii, ranging from zero velocity at zero radius to a maximum rotary velocity at $5 \frac{1}{8}$ inches radius, and falling off again at larger radii. It is interesting to notice that the maximum rotary velocity occurs at the same radius as the maximum axial velocity. The efficicncy of the helical fan was increased by putting rounded backs on the blades, in the same way as with ordinary flat blades. The experiments accordingly showed that the helical blades did not possess advantages over the ordinary nonhelical blades.

Negative Slip.-The apparent negative slip sometimes noticed in a screw-propeller occurs when the speed of the ship is greater than the speed of the screw-propeller, that is, greater than the product of the pitch multiplied by the revolutions, the pitch being calculated from the front or face of the blades. It has been regarded by the anthor in page 457 as probably due to the effect of the thickness of the blades and their round backs. On this point he has since carried out some further experiments. A three-bladed helical airpropeller was tried at 600 revolutions per minute. The angle of the tips of the blades being about $10^{\circ}$ to the plane of rotation, the pitch was $1 \cdot 1$ foot, as shown in Fig. 51, Plate 91. The speed of the screw was therefore 660 feet per minute at 600 revolutions per minute; while the mean velocity of the air as measured in the delivery tube was 650 feet per minute, showing a small positive slip. The blades were of sheet brass 1-16th inch uniform thickness, so that the pitch of their back and front faces was the same. Curved backs were then slipped on, giving each blade a plano-convex section, as shown in Figs. 52 and 53. The mean velocity of the air now obtained at 600 revolutions per minute was 783 feet per minute, the air travelling 123 feet faster than the speed of the screw when the pitch is measured from the front face of the blades. The apparent negative slip was therefore $18 \frac{1}{2}$ per cent. With finer pitch the negative slip for thick blades was further augmented. With a coarser pitch of 3 feet, 
Fig. 50, the results were reversed, and a fair amount of positive slip was obtained. In serew-propellers it has been noticed that negative slip occurs when the pitch is fine; moreover for reasons of strength a screw-propeller has its blades made with rounded backs of varying thickness, so that the transverse section of the blades is nearly plano-convex. These experiments show that the phenomena and conditions of apparent negative slip in air propellers and in water propellers correspond closely; and they seem to lead to the conclusion that apparent negative slip is due to not considering the effect of the backs or non-propelling faces of the blades.

Relation of Revolutions and Air Discharge.-The law of discharge, which, as stated on page 446 , was verified in the six fans numbered 1 to 6 , has since been again verified with two fans of the same diameter, namely 2 feet, but more powerful as air dischargers, that is, having higher volumetric efficiencies. The measurements of the less powerful of the two new fans are shown plotted in Fig. 27, Plate 83, in which they are seen to form practically a straight line $\mathrm{NN}$. At 400 revolutions 2,150 cubic feet were discharged per minute; at 600 , 3,420 ; at $800,4,440$; at $1,000,5,700$; and at 1,200 revolutions per minute 6,790 cubic feet were discharged. The volumetric efficiencies at the respective speeds were $86 \cdot 0,90 \cdot 6,88 \cdot 4,90 \cdot 8$, and $90 \cdot 2$ per cent. These figures give a mean volumetric efficiency of $89 \cdot 2$ per cent. The sections of the blades were plano-convex. The second new fan, being a still more powerful air-discharger, delivering about 4,000 cubic feet at 600 revolutions per minute, followed also the same law. Thus, for the fans tested, the law seems to hold good within ordinary limits of speed, inasmuch as it is not the general practice to run a 2 -foot fan above 1,200 revolutions per minute. In Figs. 56 and 57, Plate 93, is shown one of the fans arranged with a thrust bearing.

Calculation of Horse-Power and Size of Fan.-The horse-power necessary for driving the fan to produce a given discharge of air is as follows, taking the barometer at 30 inches of mercury and the air temperature at $60^{\circ} \mathrm{Fahr}$., which are atmospheric conditions near 
enough for ordinary calculations, and the mechanical efficiency at 30 per cent. If $d$ be the diamoter of the fan in feet, $a$ the area of the fan dise in square feet, $V$ the velocity of the air in feet per second, and $Q$ the quantity of air discharged in culic feet per second :-

$$
\text { Mechanical efficiency }=0 \cdot 3=\frac{\text { horse-power in air discharged }}{\text { horse-power to drive fan }}
$$

Whence by substitution from formula (7) in page 447

$$
\text { Horse-power to drive fan }=V^{2} Q \times 0.00000215 \div 0 \cdot 3
$$

Substituting the value of $V=\frac{Q}{a}=\frac{4 Q}{\pi d^{2}}$

$$
\text { Horse-power }=\frac{Q^{3}}{d^{4}} \times 0.0000115 .
$$

Taking the volumetric efficiency at 90 per cent., this for a 2 -foot fan means a discharge of 3,400 cubic feet at 600 revolutions per minute, inasmuch as 3,420 cubic feet were discharged at 600 revolutions per minute by the less powerful of the two new fans tried above (page 466). Thun $0.9=\frac{Q}{U r^{2}}$ (page 448), where $U=$ $2 \pi r \times R=$ velocity of tips of blades in feet per second, and $r=$ radius of fan in feet, and $R=$ revolutions per second. Hence,

$$
R=\frac{Q}{0.9 \times 2 \pi r^{3}}=\underset{2}{Q}=\underset{7 r^{3}}{\text { nearly. }}
$$

The mechanical and volumetric efficiencies here assumed may approximately be obtained with fans working under ordinary practical conditions and with free inlet and outlet.

These relations mean that for a given discharge of air tho horse-power required to drive the fan varies (9) as the square of the velocity of the air ; and also that the horse-power varies (10) directly as the cube of the quantity of air discharged, and inversely as the fourth power of the diameter of the fan. With the same fan the horse-power varies (10) as the cube of the air discharge; and the air discharge varies (11) as the speed of revolution. The height of the column of water in a water-gange varies as the square of the velocity of the air.

The three following recommendations are therefore arrived at. First, the velocity of the air passing through a fan should be as slow 
as practicable. Second, the diameter of the fan should be as large as practicable. Third, the pressure of the air passing through the fan should be as small as practicable. The great feature of propellor ventilating fans is that they may be made to comply with these conditions as nearly as possible. This kind of fan is essentially a ventilator, and its principal object is to move a large volume of air at a slow velocity and at atmospheric pressure.

In order to show the great effect of the area of the fan and the velocity of the air passing through it, the horse-power has been calculated as follows for driving five fans, ranging from 2 to 4 feet diameter and each propelling 6,000 oubic feet of air per minute:-

\begin{tabular}{cccccc} 
Diameter. & \multicolumn{3}{c}{ Horse-power. } & \multicolumn{3}{c}{ Velocity of Air. } \\
$2 \mathrm{ft.}$ & $\ldots$ & 0.72 & $\ldots$ & $1,910 \mathrm{ft}$. & por min. \\
$2 \frac{1}{2} \mathrm{ft}$. & $\ldots$ & 0.29 & $\ldots$ & 1,224 &, \\
$3 \mathrm{ft.}$ & $\ldots$ & 0.14 & $\ldots$ & 818 &, \\
$3 \frac{1}{2} \mathrm{ft.}$ & $\ldots$ & 0.071 & $\ldots$ & 623 &, \\
$4 \mathrm{ft}$. & $\ldots$ & 0.045 & $\ldots$ & 477 &,
\end{tabular}

Hore it is seen that the largest fan would require only $6 \frac{1}{4}$ per cent. of the horse-power required by the smallest fur propelling the same volume of air.

For tunnel ventilation, upon which the author was consulted by the Board of Trade and gave evidence before the Ventilation of Tunnels Committee in connection with the Metropolitan Railway, it might well be required to deliver 250,000 cubic feet of air per minute. Then employing formulæ (9) and (11) for determining the power and size for a suitat,le propeller fan with free inlet and free outlet, the diameter, horse-power, and speed of the fan, and the dynamic pressure and velocity of the issuing air would be severally as follows :-

Diameter. $\begin{aligned} & \text { Horse- } \\ & \text { power. }\end{aligned} \begin{gathered}\text { Revs. } \\ \text { per min. }\end{gathered}$ Water gauge. Air Velocity.

$\begin{array}{llllllllll}10 \mathrm{ft} . & \ldots & 83 & \ldots & 348 & \ldots & 0.65 \text { inch } & \ldots & 3,180 \mathrm{ft} . \mathrm{p} . \mathrm{min} .\end{array}$

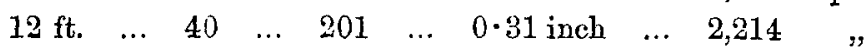

$\begin{array}{lllllllllll}14 \mathrm{ft} . & \ldots & 22 & \ldots & 127 & \ldots & 0.17 \text { inch } & \ldots & 1,626 \quad,\end{array}$

$\begin{array}{llllllllll}16 & \mathrm{ft} . & \ldots & 12 & \ldots & 106 & \ldots & 0 \cdot 10 \text { inch } & \ldots & 1,242\end{array}$ 
The calculations for the larger fans are made on the assumption that these follow the same laws as the smaller.

It will thus be seen that, while the mechanical efficiency of a series of fans can be the same, yet their efficiency as ventilators, reckoned in volume of air moved per horse-power, can vary to a considerable extent; and a fan of high mechanical efficiency may discharge a small quantity of air per horse-power, as occurs in centrifugal fans when pressure is necessary. For example, in a test carried out by Mr. Bryan Donkin of a 2-fout centrifugal fan, with free discharge the fan delivered 1,995 cubic feet at 1,324 rerolutions per minute, giving a mechanical cfficiency of $5 \cdot 2$ per cent. and requiring 1.92 horse-power; it therefore discharged 1,039 cubic feet per minute per horse-power. When the outlet was baffled so as to give a mechanical efficiency of 40 per cent., the discharge per horse-power fell to 700 cubic feet per minute. Now an air propeller of the same diameter, tested by the author at the same speed of 1,324 revolutions per minute, moved 7,550 cubic feet per minute, and absorbed 1.4 horse-power; this is equivalent to 5,400 cubic feet per minute per horse-power. The relatively greater amount of power required for the centrifugal fan with free discharge was here due to the high velocity of the air passing through the small inlets at the centre and the small outlet of the centrifugal fan; while in the propeller fan the area of passage for the air was nearly equal to the fan disc. In the centrifugal fan there was also the greater internal loss due to skiu friction. The purpose of the two fans was of course quite different: the propeller fan was for volume of air without compression, the centrifugal for volume with compression. Where the propeller fan is employed in drawing air through contracted holes or tortuous flues, the adoption of the central dise becomes important. In Table 5 (page 462) are given results of experiments with contracted inlet, and with the fan revolving partly outside the air delivery tube. The fin has since been tried completely inside the tube, and drawing air through a tortuous flue; and it has been found that, with the same power and speed of fan, the presence of a central disc of slightly conical shape increases the amount of air discharged by between 40 and 50 per cent. 
The author's thanks are due to his assistants, Mr. S. G. Lovell, Mr. H. G. Woolley, and Mr. A. M. Morgan, for their help in carrying out the experiments and preparing the drawings.

\section{Discussion, 30 April 1897.}

Mr. WALKER illustrated the paper by means of experimental apparatus which he exhibited in operation. A pair of three-bladed fans 24 inches diameter, one of them reversed to face the other, were fixed about $2 \frac{1}{2}$ feet apart on the same spindle, so that both ran at the same speed, and each acted to propel a current of air inwards against the other. Between them was a cardboard disc of the same diameter, loose to slide and turn freely upon the spindle. Obviously it assumed a position midway between them when they were in action, the pressure on each side of the dise being equal, because the blades of both fans were flat, and were set at the same angles, namely $20^{\circ}$ to the plane of rotation. On now adding rounded backs upon the blades of one of the fans, giving them a plano-convex section, its power was so much increased theroby that it blew the disc away from it along the spindle, and forced it right up against the opposing unbacked fan.

On then surrounding the same fan with a short cylindrical casing, projecting about 3 inches beyond each face of the fan and just clear of the tips of the revolving blades, it was seen that the additional power gained by the rounded backs of the blades was not merely neutralised but was overpowered, so that the disc was blown back again by the opposite unbacked fan, and forced up against the encased round-backed fan. This was because the addition of the casing blocked the feeding from the tips of the blades, so that the fan could not take in so much air, and consequently could no longer discharge so much as it had done before the casing was added. 
Another experiment illustrated the effect of the arrangement. represented in Fig. 43, Plate 90, where a three-bladed fan of 24 inches diameter worked in one end of a delivery tube, of which the outer end was contracted by a plate containing a central outlet hole of only 6 inches diameter. A ribbon hanging in front of the outlet showed how slight, if any at all, was the issuing current of air, so long as. the central portion of the fan remained open and thus allowed the air propelled into the tube to leak back again through that part, the speed of the fan at the centre being so much slower than at the tips. of the blades. As soon as a loose circular disc of 18 inches diameter was placed upon the spindle, close in front of the fan, it blocked the centre of the fan and prevented this backward leakage; and the ribbon showed that the strength of the issuing current was largely increased, indicating a fair amount of static pressure in the delivery tube. If the disc was placed at a little distance in front of the fan, the pressure of the air trying to leak out backwards through the centre of the fan gradually pushed it back close up against the face. of the fan.

For illustrating the rotary motion of the air discharged from the fan, the delivery tube was removed, and upon the fan spindle werg: placed three loose pairs of vanes, of 6 and 9 and 12 inches radius, but parallel to the spindle, so that they were not acted upon by the axial motion of the air propelled by the fan, but only by its rotary motion. The nearest pair, of 6 inches radius, was about 12 inches. in front of the fan, the middle pair about 18, and the furthest about. 24 inches from the fan. It was seen that, with these positions of the vanes, and at the speed at which the fan was running, the middle pair, of 9 inches radius, revolved faster than either of the others: showing clearly that somewhere in that neighbourhood there must be a maximum rotary velocity in the current of air propelled by the: fan. The angle of the fan blades was $35^{\circ}$.

In the same experiment a row of ribbons suspended across the: current, all in the same cross section at a distance of about 30 inches. from the fan, showed that there was but little spread of the air radially. The air evidently issued in a cylindrical column from the fan, and preserved that form so closely that the two extreme ribbons. 
(Mr. Walker.)

on either side, hanging one inch beyond the radius of the fan, were :seen only just to flutter; while those between them, being within the range of the air current, were blown forwards by its passage.

Mr. C. Humphrey Wingfield said that, while fully appreciating the great amount of labour and care which the author had expended upon these experiments, and the value of the material he had thereby accumulated for the benefit of engineers, he differed somewhat from him in the conclusions he had drawn from the experiments. In page 440 it was said that the mechanical efficiency of the ordinary centrifugal blowing fan was a maximum at a certain contraction of the outlet, which gave a certain static pressure. In a valuable paper on centrifugal fans, by Messrs. Heenan and Gilbert, read before the Institution of Civil Engineers (Proceedings 1895, vol. exxiii, page 272), their results had been plotted in characteristic curves, ssmewhat similar to those now exhibited, and showing at almost every speed a maximum efficiency with a particular size of orifice; but in their experiments he could see no indication of any particular static pressure which gave a maximum efficiency. Four different diagrams were given, for different speeds and different pressures; and as the speed of the fan increased, so the efficiency increased. There was no indication of a maximum efficiency, which diminished again when the velocity was further increased. In page 440 of the prcsent paper it was remarked that the flow of air was not assisted by any static pressure, but was due only to its velocity. There was always the pressure of the atmosphere, without which the air would hardly enter the fan at all ; but as flow and velocity seemed to be convertibly terms, the meaning of the remark did not appear clcar.

In page 441 it was stated that the velocity of the air varied greatly in different positions in the same cross section of the delivery tube; and in Fig. 23, Plate 81, were shown four positions in which the anemometer had been placed for trying the velocity of the air. It appeared to be assumed that, all round any one of the four concentric rings there shown, the velucity was the same as at the particular point in that ring at which the anemometer had been placed. In Messrs. Heenan and Gilbert's 
experiments (page 279) four positions of the water-gauge had been tried, all in the same cross section of the delivery tube of 8.9 inches diameter, two near the centre and two near the outside. The air velocity varied greatly: from 118 feet per second at $3 \cdot 1$ inches radius on one side of the centre it fell to only 86 feet per second at the same distance on the opposite side; while at 1.1 inch radius it was 112 feet on one side and 90 feet on the opposite side of the centre. Unless therefure a great number of places had been tested in that way, there would seem to be a certain amount of assumption as to what the actual velocity was in any place at which it had not been ascertained by the anemometer.

In page 442 mention had been made of an experiment with a thin plate of small area, attached to the end of a lever: which he presumed had been only for the purpose of seeing how it would answer, as it did not appear that any results so obtained had been used for plotting the curves.

In connection with the statement in page 446 that for constant angle of blades the air discharge varied as the speed of revolution, it would be interesting to know whether it had been found that with a very high speed the air discharge per revolution fell off. It was conceivable that the fan might be driven at such a high speed that the air would not enter rapidly enough to keep the discharge up in the same proportion.

In page 448 was given a formula for the volumetric efficiency. No matter what was the contrivance dealt with, efficiency he believed always had practically the same meaning: certain theoretical assumptions were made upon which a certain maximum result could be attained, provided everything wore perfect; and the efficiency was the ratio which the result actually obtained bure to this theoretical maximum result. In order that the comparison might be possible, both results must be expressed in the same terms. In the formula given for volumetric efficiency, namely $\frac{Q}{U r^{\tilde{2}}}$, the numerator $Q$ denoted cubic feet per second; and therefore, in order that the ratio might be a measure of efficiency, the denominator of the fraction must also be cubic feet per second. Now $U$ denoted the velocity of the tips of the blades in feet per second, or $U=2 \pi r \times$ revs. per second; therefore 
(Mr. C. Humphrey Wingfield.)

the denominator became $2 r \times \pi r^{2} \times$ revs. per second, or diameter in feet $x$ area in square feet $x$ revs. per second. This could not possibly represent cubic feet per second,* except in the one case where the pitch was equal to the diameter; and as it was not in the same terms as $Q$, the fraction did not represent at all the efficiency as defined above. It would be seen that the angle of the blades was neglected, whereas with a fan of the screw-propeller type the pitch ought to be included; otherwise it would seem as though blades parallel to the plane of revolution, and therefore with no pitch, would give the same value to the ratio, that is, would give the same efficiency, as a propeller having any pitch that might be selected. As pointed out in the paper, this ratio was due to Professor Rateau, who had given the same formula for centrifugal fans in the discussion upon Messrs. Heenan and Gilbert's paper (page 322); but it seemed as thougb, by there styling it the "coefficiont of delivery," he had guarded himself against calling it "efficiency." It was true that in the diagram accompanying Professor Rateau's remarks (page 322) the result of applying this ratio was plotted under the name of "volumetric efficiency," together with what was called "pressure efficiency"; but as he had given a special warning that "the manometric power should not be confounded with the manometric efficiency," it seemed probable that the word "efficiency" had been placed on the diagram by mistake in both cases. By substituting the pitch for the diameter involved in $U$, the ratio quoted in the paper would at once bocome a measure of efficiency. and would be $Q \div$ (pitch $\times$ area $\times$ revs. per second $)$. It was alleged in page 448 that the formula $Q \div U r^{2}$ was shown to be based on correct principles by the fact that it gave a constant efficiency for the same fan at all speeds. But since the air discharge varied as the speed of revolution, such a formula as this could not give any other than a constant result; and even if any other dimension, such

* In order to obtain cubie feet per second it is necessary to multiply the area of fan disc by the velocity in a direction normal to the plane of the disc. The product of the diameter nultiplied by the revolutions per second is a measure of circumferential velocity, that is, velocity in the same plane as the disc; hence it does not fulfil this essential conditicn. 
as the diameter of the fan spindle for instance, were substituted for the diameter of the fan, the efficiency so calculated would still be constant.

In dealing with the angles of the blades (pages 448-9), he enquired how the angle had been measured for the curved blades: whether by a chord line across the blade, joining its lateral edges. It was always difficult to say what was the effective pitch either of flat or of curved blades like those shown in the drawings, which were not helical surfaces. If they were, the pitch would be the same everywhere, and the base of the blade would be twisted more parallel to the shaft than the tip was; but with the flat or curved blades here shown, the pitch, if it could so be called, was much less at the shaft than at the tip. The propelling action of the fan upon the :air in the direction parallel to the axis was therefore slower at the centre than at the circumference: a fact which would account for the direction of eirculation of the air through the fan, when worling against pressure, as noted in page 455 .

Allusion had been made to the fact that air entered round the edge as well as at the side of the fan (page 452). It had been pointed out by Mr. Froude, and was now generally recognised, that, with marine screw-propellers working in water, at least half the total acceleration of the water took place before it entered the propeller; and there could be no doubt that the same was equally true of air propellers of the kind described in the paper. This necessitated a convergence of the streams of air flowing towards the fan, and it might be expected that some air would enter round the edge. It was surprising however to see from Fig. 27, Plate 83, and Fig. 35, Plate 87, how large a proportion of the total air delivered was drawn in in this way. In passing through the fan the air was further accelerated, whereby a further convergence would be caused, which would be increased by the fact, previously alluded to, that less air was delivered from the centre of the fan, on account of the pitch being less there than at the circumference. The minimum axial velocity therefore of 175 feet per minute in Fig. 35 (page 453), which was measured at a radius equal to that of the fan, he thought was probably the speed of an induced current, and not of the air 
(Mr. C. Humphrey Wingfield.)

which had passed through the fan, since the latter would probably form a column of smaller diameter.

In page 456 it was pointed out that with a contracted orifice, as in Figs. 43 and 44, Plate 90, the fan was better for exhausting, as in Fig. 44, than for propelling, as in Fig. 43. One reason of its. superiority for exhausting seemed to him to be that in Fig. 44 the air could not go directly through the centre of the fan, as it could through an open fan, but was here obliged to rotate with the fan; thus the centrifugal action of this part of the fan was brought into play, and being half uncovered all round the edge it could act. largely in that way, in combination with the propelling action of the outer ends of the blades. In Fig. 43, where the air was going inwards round the circumference of the fan, the centrifugal action was tending to stop it from entering; the centrifugal current was crossing the entering stream, and throwing it outwards against the edge of the tube, and thereby creating an obstruction.

In relation to the rexed question of negative slip (page 457) the author's experiments were exceedingly interesting. The experiment just witnessed was conclusive as to the addition of the rounded backs upon the blades increasing the virtual pitch and the delivery. What their bearing was upon negative slip would require to be thought out. From the results of Mr. Froude's propeller experiments a table in a simple form had been published in Mr. Barnaby's book on Marine Propellers (3rd edition, Table I, page 73), from which the speaker had constructed a formula (page 64) to show, by using it in conjunction with the table, when negative slip could be produced. A number of instances had been got together, in which negative slip had been reported; and in these it had been found that the pitch was fine, and that the formula showed that the propeller ought to have negative slip. It had not been arrived at theoretically, but was simply based on the assumption that the experimental results had been correctly observed and recorded; and he had not gone urther into the matter than to find a formula which should fit them. A theory however had been elucidated by Mr. Barnaby, which completely accounted for the observed phenomena. of sc-called uegative slip. 


\section{Adjourned Discussion, 3 November 1897.}

Mr. WALKER repeated the experiments exhibited at the previous. meeting (pages 470-2), showing the increased efficiency obtained by adding rounded backs upon the fan blades; and the diminution of efficiency resulting from surrounding the fan with a short cylindrical casing, so as to prevent the feeding from the tips of the blades.

On substituting $\dot{a}$ six-bladed fan of the same diameter in place of one of the three-bladed fans, it was seen that the six-bladed was somewhat less powerful than the three-bladed. A disc sliding loose upon the spindle between the two fans mounted thereon, which were blowing against each other, was seen to be blown rather further away from the three-bladed fan, instead of remaining midway between them, as it would do if they were both of equal power.

For further illustrating the effect of the arrangement represented in Fig. 43, Plate 90, where a three-bladed fan of 24 inches diameter worked in one end of a delivery tube, of which the outer end was. contraeted by a plate containing a central outlet hole of only 6 inches diameter (page 471), he had now prolonged the central outlet by a nozzle of 6 inches diametor and about 18 inches length, in which a. small round weighted disc facing the current was carried on the short arm of a light vertical lever, whose long arm served as an index. When the fan was driven so as to propel air outwards through the nozzle, the deflection of the lever from the vertical was seen to be but slight; and a light silk ribbon suspended in front of the orifice was hardly disturbed by the issuing air. When however the driving strap was crossed, so that the fan ran at the same speed in the opposite direction, it drew air in through the same nozzle to so much greater an amount that the lever was deflected through a much larger angle on the opposite side of the vertical ; and the silk ribbon was sucked right into the nozzle.

With the same apparatus was demonstrated the increased efficiency obtained by placing a loose circular dise of 18 inches diameter close in front of the centre of the fan of 24 inches diameter, whereby the air propelled forwards from the tips of the blades was prevented from escaping backwards through the centre of the fan, where the speed. 
(Mr. Walker.)

of the blades was so much slower than at their tips. If however the central disc were placed behind the fan, instead of in front, its action created a partial vacuum in the centre of the fan, and converted it into a sort of centrifugal fan. On the principle of the central disc in front of the fan, and after a long series of experiments, he had now designed a fan driven by a central motor, which was placed immediately in front of the fan so as to act the part of the central disc. This fan had a maximum efficiency of about 70 per cent. when running at the comparatively slow speed of 600 revolutions a minute. Though seemingly so small, it was really a powerful fan. The air was discharged away from the front of the fan in a cylindrical column. It would be noticed there was not much spread of the air laterally, because ribbons hung outside the line of the column remained vertical, whilst those within the line of the column were blown straight out horizontally.

The rotary velocity of the air discharged from the fan was illustrated by pairs of vanes, parallel to the fan spindle and revolving loosely upon it. The maximum rotary velocity occurred at a radius of about 5 inches with a fan of 21 inches diameter. The helical twist produced in the air as it left the fan was rendered apparent by holding in the current a long rectangular flag of light cloth, which was seen to curl itself up in a rough manner into a more or less helical surface: so that, while the inner end of the flag formed a horizontal diameter of the air current, the outer end was twisted into a vertical diameter.

Mr. M. Holnoyd SmrtH had watched with interest the experiments just made, the author having been good enough to invite him from time to time to witness the experiments made in his laboratory. One feature about them, which had especially attracted him, would be noticed on comparing the original paper read half a year ago with the supplementary paper now read. The comparison showed that the author had advanced a step. In the first paper he had been speaking somewhat doubtfully on the question of induced versus produced currents; whereas in the second paper he now spoke much more positively. Some fifteen years ago, when investigating the 
action of birds' wings, he had himself been led to consider somewhat carefully the difference between produced and induced currents; and he had then come to the conclusion, which the present experiments seemed to prove correct, that the fan's principal work, almost its total work, consisted in inducing a current, and not in producing or propelling it. In the present papers one face of the fan was spoken of as the front or propelling side of the fan; and then the effect produced by making some alterations to the rear side or back of the fan was described. To himself it appeared that what was usually called the front or propelling side of the fan did very little at all, and that nearly all of the work was done from the back of the fan. Certain experiments which he had carried out, though not so extensive as the author's, were almost analogous to them. One had consisted in putting a couple of fans upon the same spindle, a few inches apart, one being driven and the other loose. If the driven fan ran in one direction so as to propel a current towards the loose fan, the latter would revolve, but slowly; if the driven fan ran in the contrary direction so as to draw an induced current from the loose fan, the latter revolved rapidly. That little experiment had led him to another, which could easily be shown on the spot, emphasizing what he should be disposed to lay down as almost universally true, namely that the back of the fan, and not the front, really did the work. On lighting a match, and striking vehemently towards it with a common Japanese hand fan, it was seen that even the most sudden approach of the fan would not blow the flame out; but on suddenly withdrawing the fan backwards away from the match, the following current of air nearly blew it out. Similarly in waving the fan quickly past the flame, if the fan were suddenly stopped just before passing the match, it produced no effect; but as soon as the edge of the fan passed beyond the match, so that the air from the back of the fan could reach it, the flame was blown out immediately. Another illustration of the same kind was afforded by supporting a piece of paper on a horizontal wire ring, and striking upwards towards it from below with the fan, whereby it was seen that no effect was produced upon the paper, which rested nndisturbed upon the ring; but on holding the fan above, and then 
Mr. M. Holroyd Smith.)

striking upwards away from the paper, the latter was drawn up immediately by the following current. These were some of the simple experiments which had led him to the conclusion that it was the induced and not the propelled eurrent which represented the most effective part of the fan's work. Of the numerous sections of fan blades shown in the drawings, it had been stated in page 451 that the most efficient was the concavo-convex, Fig. 4, Plate 79, having the front or propelling face concave. Could not this result be fairly attributed to the fact that this shape represented, more closely perhaps than any other of those shown, the section of a bird's wing? It must be so, he thought, because he had found that a bird's wing had just these curves. It was the convex side of the wing that was uppermost when the bird was flying, and he believed the convex upper side of the wing had just as much efficiency in the process of flying as the concave under side. The bird had to accomplish a double act, not only sustaining itself in the air, but also propelling itself forward; and the upstroke and the downstroke of the wing were both giving the propelling force. What nature had done might safely be relied upon as being always the best; and it was a wonder that nature's example had not been followed before in the design of ventilating fans. In now following that example he was glad to see that the author was produeing the remarkably good effects which he had been able to show in the experiments here exhibited.

Colonel Perton Phelps, late R.E., though he could not discuss the reasous for the results of the experiments which had just been witnessed, was greatly interested in the whole subject, having formerly been in the Public Works Department in India, where he had had a good deal of experience in the designing, building, and ventilating of barracks; and it appeared to him that the results of the experiments now shown put a new aspect on the way in which air might be mechanically introduced into buildings. Under the old method, with the centrifugal blowing fan, the air was forced in; the current went in one straight line through the room from the point of inlet to the point of outlet, and a large space on either side was stagnant; indeed not only stagnant, but he was not sure that it 
did not become a reservoir for a large portion of the foul air which was inside the room, but was unable to escape. From the present experiments and paper he had gathered that the fans designed by the author enabled a large volume of air to be propelled at a low velocity; so that the probability of its being able to spread itself rapidly when it entered a room was much greater than by the old method of the centrifugal fan. There was also another point to be noticed about these experiments, with regard to the difference between induced and propelled currents. The great difficulty with powder magazines was to keep the interior atmosphere as nearly as possible at an equality with the external atmosphere; it was almost impossible to do it completely. But it occurred to him whether it would not be practicable to arrange that the propelled air discharged from one of these ventilating fans might also be accompanied by an induced current drawn out at the roof of the building: not only should the air be propelled into the inside of the magazine, but also the air should be sucked out from the top. When the warmer external air came into contact with the cool internal air of the magazine, the moisture in the warmer air must be deposited at once; if this internal air could be removed rapidly, the degree of dampness inside the magazine would be considerably diminished. From these experiments it seemed to him that this could to a certain extent be accomplished. In the vessels which were employed in the Persian Gulf, the Peninsular and Oriental steamers, and the British Indian Steam Navigation vessels, going to and from India through the great heat of the Red Sea, he could not understand why a system of ventilation worked by a fan had never been established, running round the ship and passing through all the different cabins. This he thought might be done at a comparatively trivial cost. Such an improvement in ship construction would be greatly appreciated by all who had to travel to and from India, and by all who had to pass a good deal of their service in as hot a place as the Red Sea or the Persian Gulf.

Sir Benjamin A. Dobson, Member of Council, thought the information furnished in the present papers would at any rate form 
(Sir Benjamin A. Dobson.).

the basis for arranging the ventilation of large buildings in the future. The question of this particular kind of propeller ventilating fan as contrasted with the centrifugal fan was highly interesting; and he hoped the author's investigations would be carried further into the action of centrifugal fans producing a propelled current. Lately he had had occasion at his own works to make himself practically acquainted with an extraordinary result. In putting up a new foundry, where each cupola was required to melt $7 \frac{1}{2}$ tons of metal per hour, the blast was naturally being produced by ordinary centrifugal fans. The fans were 40 inches diameter, running at 1,500 to 1,550 revolutions a minute, and had been absorbing from 28 to 30 horse-power. The last cupola put up had a 48-inch fan running at 925 to 950 revolutions per minute, which was melting the $7 \frac{1}{2}$ tons of metal per hour, but was taking only 10 to 12 horse-power. This extraordinary result might not have been so apparent, had it no been for the fact that at the same time a change had been effected in the driving power, by putting an electric motor to each of the fans; and then the voltmeters and the ammeters on the motors driving the fans disclosed at once the fact that one of two cupolas was doing the same work with from 10 to 12 horse-power for whick the other required from 28 to 30 H.P. The result was so extraordinary that he had made a large number of experiments, and had found that the effective result of a centrifugal fan, as regarded its diameter, varied even more than the present paper had shown to be the case with these propeller ventilating fans. Enough was not yet known, he thought, about the means of moving air, either for ventilation or for blast or for any other purposes for which it was attempted to move it. The present paper he considered was one of the most interesting and valuable he had ever had the pleasure of listening to; he only hoped the investigations would be carried yet further, and that he might thus be furnished with data for explaining such an extraordinary occurrence as he had mentioned, of which in the: meantime he should be happy to furnish the precise particulars.

Sir Frederick Bramwell, Bart., Past-President, mentioned that. a good many years ago he had been engaged in conducting experiments 
which ultimately led to the introduction of the Griffiths screw into the navy. The blades of the screw were made upon the principle of an increasing pitch, increasing he believed from the leading edge to the trailing edge, somewhat as shown in Fig. 4, Plate 79. To his great surprise it was found that the leading edge of the forward or working face of the propeller blades, after it had been at work for some months, was covered with a green sea-weed, while the back of the blades, which had been thought to be doing nothing, was bright. That greatly tended to corroborate what had been shown in the present experiments. Those old experiments had also included some with a screw, the pitch of which could be varied; and it had been found that negative slip could always be obtained if the pitch were uade fine: it was perfectly easy with a fine pitch of screw on a ship with full buttocks to get negative slip.

In the experiment now shown, in which a fan appeared to produce so poor a result in driving air through a tube which terminated with a flat end containing a small central outlet hole, he enquired whether the effect had been tried of terminating the tube with a conical end tapering down gradually to the size of the outlet hole.

Mr. Edward Furness had found that, in discharging air through a conical nozzle tapering down to the outlet orifice, the area of the outlet orifice was the sole measure of the discharge that would pass through, whatever might be the capacity of the cone. The air would not pass out any more abundantly for the nozzle being enlarged internally; it passed only as rapidly as the outlet orifice at the small end of the cone would allow. Inside the cone the air was simply deflected by the tapering walls, and formed eddies inside the conical nozzle; aud it was the outlet orifice alone which determined the quantity of the air that passed throngh.

Mr. Bryan Donin, Member of Conncil, desired to express his congratulations to the author, not only upon the excellent diagrams shown upon the wall, but also upon the illustrative experiments he had here exhibited with such interesting results. The paper seemed to him most exhaustive, dealing with such a 
(Mr. Bryan Donkin.)

great many experiments and facts. The quantities of air and the horse-powers had been carefully measured; and these were seldom given. The experiments had been made by varying only one factor at a time, which was so essential for generalising and for drawing proper conclusions. Having himself also made many experiments on the measurement of air, in testing about a dozen centrifugal fans, ${ }^{*}$ it had occurred to him to suggest the desirability of further experiments by putting some sort of baffling diaphragm, perforated zine or wire netting of half-inch mesh, across the whole area of the delivery tube, in order to see its effect in checking the revolving motion of the discharged air.

In testing the anemometer at Kew (page 442) it had not been stated how it was done, which was an important point. There were. two ways of testing anemometers: one was by moving the anemometer in a circular path at the extremity of a long radius ; and another way, which had been used in Germany, was to move it in a straight path. The latter seemed to him to be the correct method.

With regard to the question of skin friction upon the fan blades, the experiments showed conclusively how much more important a part the back of the blade played than the front; and he suggested it would be desirable for the blades to be varnished and coated with some sticky substance, so as to imitate dirty blades. If these ventilating fans were used, as they could be, for inducing draught in low factory chimneys, for instance, the blades would soon get dirty; and he should like to know the effect of the dirty surfaces on the efficiency of the fan.

As to the best number of blades, it appeared from page 463 that with fans 24 inches diameter running at 600 revolutions per minute, with two, three, and six blades, the three blades came out the best, but only about 10 per cent. better than the six blades with that particular diameter and speed. The reason of the difference he hoped the author would explain; and he imagined that if the propellers were made 4 or 5 feet diameter the effect of the number of blades might not be exactly the same as with a propeller only 2 feet diameter; but this was a question which ought to be treated experimontally.

* Proceedings Institution of Civil Engineers, rol. cxxii, 1895, page 265. 
As to the effect of the back of the blades, it would be interesting to ascertain by means of Pitot tabes the pressure not only at the front of the blades but also at the back, at different parts of the blades. There was a large field for making experiments and obtaining valuable results in this way.

Mr. J. Walten Gibes, Liverpool, having three or four years ago had some difficulties with fans, had been led to make a considerable number of experiments at great expense, many of which were identical with those that had been carried out by the author. With reference to the number of blades, he had certainly come to the same conclusion, namely that a large number of blades was not at all necessary; in fact the better result was obtained from the smaller number of blades. The thickness of blades was a point he had not looked into. As to the electric motors, he had dismissed altogether the idea of having an open motor, for the reason that the dust always natarally impinged upon any motor which might be used for driving a fan direct; therefore it seemed essential that the motor must be enclosed. The results of some experiments he had made in this direction had turned out satisfactorily; and it had been managed so as to get rid of any possibility of heating to an undue extent in a closed motor. There was no doubt whatever in his own mind that fans of this class should have their circumference open; his own experiments had also confirmed exactly the author's conclusions in this particular. Further still, he thought there could be no question that the effect of the fan in producing an induced draught was vastly greater than any effect it could produce in forcing the air in front of it. It was far easier to draw the air from behind by a fan of this class, which drew a large volume, than to propel a column of air in front of the fan. In regard to ship ventilation (page 481), at the present time several steamers were being fitted with fans, for the object which had been referred to. Besides the two modes already mentioned of testing anemometers (page 484), one other method which he had employed consisted in filling a closed ressel with a known volume of water, and putting the anemometer in a tube through which the air was then drawn into the ressel by allowing the water to 
(Ir. J, Walter Gibbs.)

escape, thus getting the known volume of entering air registered by the anemometer. This plan he thought preferable in certainty to the swinging-bar test.

Mr. C. Homphrex Wingfield, having on the previous occasion taken exception to the adoption of the formula $\frac{Q}{U r^{2}}$ for the volumetric efficiency of these dise fans, and having fully explained his reasons for so doing, need only reiterate what he had then said upon this point (pages 473-4). In the supplementary paper he noticed that the same formula had still been employed (page 467). In page 464 the great similarity between Fig. 54, Plate 92, and Fig. 35, Plate 87, had been pointed out, as showing that the helical form of blade had not rendered the velocity of discharge more uniform than it was with flat blades; and again in the next paragraph (page 465) it was said that the experiments showed that helical blades did not possess advantages over the ordinary non-helical blades. Now the angle of the flat blades at their tips was $35^{\circ}$ to the plane of rotation (page 453), while the angle of the helical blades was only $27^{\circ}$ (page 464), so that the flat blades had a pitch 37 per cent. greater than the helical blades. Notwithstanding this greater pitch of the flat blades, the maximum axial velocity of the air discharged from the helical blades was 1,340 feet per minute (Fig. 54), in comparison with only 1,230 feet per minute from the flat blades (Fig. 35); it was thus considerably greater in proportion to the piteh, which was the ouly true way of measuring volumetric efficiency. The mean axial velocity, which should preferably be compared, was not stated in the paper; but as both the maximum and minimum velocities were greater in the helical than in the flat-bladed fan, it seemed fair to assume that the mean velocity was greater also, especially in view of the great similarity pointed out (page 464) in the forms of the velocity curves, Figs. 54 and 35. The value of the rounded backs of the fan blades he thought had been fully proved by the author's experiments, which had shown clearly that the rounded backs did produce practically an increased pitch of blade, so that the virtual pitch was somewhere between the pitch of the back and that of the 
front. Referring to the experiment in which the motion of a hand fan, moved quickly towards a lighted match, had failed to blow it out (page 479), this was a good illustration of the fact that a flat plate moving through the open air in a direction at right angles to its surface could not disturb the air far in advance of it; and only on encountering the face of the plate did the air make its escape laterally round the edges of the plate, where a disturbance then arose by the air flowing in eddies round from the front to the back to fill ap the partial vacuum created in the wake of the plate's motion. This however did not seem to him to prove in any way that an induced draught by suction would be more effective than a current propelled by pushing it in front of the fan, as the action was quite different from that of a rotary fan, which did not move along like a piston in a direction normal to the surface of its vanes, but acted partly by wedging the air out of the way and partly by centrifugal force.

Mr. Thомаs MUd, Member of Council, highly appreciated the paper and the experiments now shown, which were in many respects quite convincing. In this connection he noticed it had been remarked both by the author and by various speakers that induced draught was hereby proved to be better than forced draught. By what he thought was rather an unfortunate coincidence these two particular terms happened at the present time to be appropriated to two methods of obtaining draught for the burning of fuel in marine boilers, namely by induced draught and by forced draught. They wero competitive plans, and he gathered from the paper that it was not intended in the least to deal with either of them. Having himself no interest whatever in either the one or the other, he thought in fairness to both it was desirable that any possible misapprehension should be prevented by recognising clearly that no attempt was made in the paper or experiments to prove that either method was better than the other. It appeared to him that what the paper was intended to prove was that a fan of this description drew air from the back of it better than it drove air from the front, and that it was an instrument which was not capable of producing pressure. This fact seemed 
(Mr. Thomas Mudd.)

to him to be well demonstrated by one of the experiments just. witnessed, in which the fan was trying to drive air through a cylindrical tube having its further end closed up except for a small central outlet hole. Here it was evident that, although the fan could get plenty of air from behind, yet, as soon as ever the cylindrical tube was filled with air at a very slight pressure indeed, the fan could drive no more air into it, because it could not produce pressure; therefore the fan could draw in no more outside air from behind, and the air which was in the cylinder would not go forward faster than a speed due to the escape through the small ontlet under a very slight pressure. Naturally enough there was consequently only a small discharge from this outlet hole. But when the fan was. reversed, and the air was being drawn in through this same small hole, and this was the only aperture through which it could enter the fan, while the discharge side was open to the full diameter of the fan, it seemed to him that it stood to reason the fan would draw very hard at the small hole.

There was one point that seemed worth alluding to, on the question of negative slip and the effect of the rounded backs of propeller blades. Some reference had been made to the mean between the pitch or angle of the face and the pitch or angle of the back, as explaining negative slip. Looking at the leading edge: of a blade, it was readily apparent that the mean angle was less than the angle of the face, and not greater; for if $\mathrm{L}$ in Fig. 59, Plate 94, were the leading edge of a blade revolving about an axis $\mathrm{XX}$ in the direction of the arrow, and ALB were regarded as the pitch angle of the face, and ALC the same for the back, it was clear that the mean angle ALD represented a smaller pitch angle than ALB. It was evidently not by looking to the leading edge therefore that the cause of the phenomenon must be sought. Examining the trailing edge $T$ in the same way, it would be found that the mean angle MTP was greater than the pitch angle MTN of the face. It would seem then that the effect, as of increased pitch, produced by the trailing half of the curved back of the blade, more than overcame the effect, as of diminished pitch, produced by the leading half. Another way to look at it was to 
regard the fluid-air or water, as the case might bo-as being shot away from the blade by the face in a direction TN; while the fluid rushing in to fill up the partial vacuum formed by the movement of the blade might be regarded as travelling in a direction TO. The two currents met each other at the trailing edge $T$, as illustrated in Fig. 58, resulting in a mean direction TP being given to the fluid, which was equivalent to a greater pitch than that of the face of the blade, and would represent in result what was known as negative slip : that is, more effect produced than was theoretically possible when the face angle only was taken into consideration. This theory of the cause of negative slip would appear consistent with the fact pointed out by Sir Frederick Bramwell (page 483), that the phenomenon was more apparent with a finer pitch than with a coarser : as would seem clear from a comparison of Figs. 59 and 60. The angle NTO between the face and the tangent to the back of the blade would be constant for any setting of the blade; and the half of it forming the increment, namely NTP, constituted a much larger percentage of increment at the trailing edge over the face angle MTN with the finer pitch shown in Fig. 60 than with the coarser pitch shown in Fig. 59. This condition favoured the result, being more felt with a finer pitch than with a coarser. The fact of the increase of pitch at the trailing edge overcoming the diminution of pitch at the leading edge-probably due to the fluid having acquired velocity when passing the trailing edge which it had not acquired when passing the leading edge-would point to the conclusion that in designing a propeller it was of greater importance to study the form of the section and the sharpness of the edge for the trailing half of the blade than for the leading half.

Mr. David Jor said his experience had led him during most of his life to look more or less closely into the relative merits of induced draught and forced draught; and he was greatly mistaken if the forced dranght at present used in the stoke-holds of ships could at all compare with the induced dranght of the existing locomotive. The finest draught he knew of anywhere, as every locomotive superintendent would agree, was the exhaust or induced draught of the locomotive. 
Mr. WALKER said the concavo-convex section of the blade shown in Fig. 4, Plate 79, which Mr. Holroyd Smith had pointed out was 'somewhat approaching the section of a bird's wing (page 480), had certainly given very good results indeed, and had been utilised in the propeller ventilating fan. Nevertheless it could not yet be definitely said which was the best section, because a long course of experimenting was still required, in order to arrive at what was really the best section. So far as the experiments had gone, they certainly seemed to show that the face of the blade should be slightly concave, and the back of the blade should be considerably more convex.

The drying of powder magaziues (page 481) was a matter of great practical difficulty. Theoretically it was simply a question of the dew-point. The great aim was to keep the temperature inside the magazine equal to the temperature outside. If these two temperatures could be kept equal, there would be no condensation when the doors were opened. The great difficulty was to keep these temperatures equal, whether constant or not; and certainly it would be interesting to try what could be accomplished in this direction by moans of artificial ventilation.

In corroboration of Sir Frederick Bramwell's experience with the Griffths screw (page 483), in his former paper in 1892 he had drawn attention to the fact (page 523) that in a screw-propeller 10 feet diameter, after some five or six months' voyaging to the Mediterranean, certain portions of the faces of the blades were covered with seaweed some inches long. The greater part of the backs of the blades was also covered with grass.

As to whether the efficiency would be increased by putting on a cone at the end of the delivery tube, instead of closing it with a flat end having a small central outlet hole (page 483), he had not yet carried rout any experiments, except only a rough one with a cardboard cone. Where the velocity was high, he was under the impression that the efficiency was increased by the adoption of the cone; but to what wextent he was unable as yet to say.

The method that he had used for baffling the outlet of the discharged air was far from uniform, consisting merely of a plate with a circular hole in the centre, placed at right angles to the axis 
of the current. On Mr. Donkin's suggestion (page 484) he had tried a perforated-zinc plate, in which the perforations were spread over an area equal to the fan disc, instead of a single central hole equal to the sum of the perforations; thus the baffling was more nniform, and somewhat better results were obtained than with the single central hole.

The method of testing the anemometer at Kow (page 484) was simply by placing it at the end of a rod, and whirling it round in a circle. That was really a most unsatisfactory method, but it was the best that he could get in this country for calibrating the anemometer. The mode of testing an anemometer by allowing a known quantity of water to flow out of a vessel (page 485) would cause a varying velocity of the air, due to the varying head of water in the vessel and the consequent varying velocity of outflow. In testing anemometers it was necessary that the velocity of the air should be constant throughout each individual test. It would therefore be better he thought to start with the measuring tank empty, and to fill it at a constant rate from another tank, thereby forcing the air out at a uniform velocity through the anemometer.

Why a six-bladed fan was less efficient than a threo-bladed (page 484) was rather a difficult question, which he was not yet able to answer with any certainty. In the six-bladed fan he was inclined to think the blades worked too closely in the wake of one another at the high speed at which the fan revolved: so that the alternate blades worked almost in a partial vacuum left by the other blades.

The fact of Messrs. Heenan and Gilbert's experiments on centrifugal fans showing at almost every speed a maximum efficiency with a particular size of orifice (page 472) seemed to him to coincide exactly with the statement in page 440 , instead of differing from it. The remark that there was always the pressure of the atmosphere to. assist the motion of the air did not apply, he thought, to ordinary propeller fans working at atmospheric pressure, where the onward motion of the air from the fan was due only to propulsive energy; being at atmospheric pressure, its flow obviously could not be, assisted by the atmosphere. 
(Mr. Walker.)

The velocity of the air was nearly uniform (page 472) all round any one of the four imaginary concentric rings shown in Fig. 23, Plate 81, although it varied considerably in the different rings.

In confirmation of the law that the air dischargo varied as the speed of revolution (page 473), he had tried powerful fans up to 1,200 revolutions per minute, and at this speed no falling off was noticed in the air discharge per revolution.

To the volumetric formula $\frac{Q}{U r^{2}}$ in page 448 objection had been taken by Mr. Wingfield (pages 473-4) on the ground that, as the numerator was in cubic feet, the denominator ought also to be in cubic feet. The latter requirement he considered was already complied with, because the velocity of the tips of the blades in feet was here multiplied by the area in square feet. The accidental coincidence that the velocity was in this particular fan a rotary velocity in the plane of the area did not in his opinion affect the value of the formula at all, as he considered it was quite legitimate to deal with velocities in different directions: just as was done in transforming the rectilinear velocity of a steam-engine piston into the rotary velocity of the crank. As to the suggestion (page 474) that the pitch ought to have been included in the formula for the volumetric efficiency, it appeared to him that it would not be convenient to include the pitch. In the first place it was difficult to say what the pitch was in these fans; and in the next place it would have to be settled whether the maximum pitch should be taken, or the mean pitch. Again there seemed no reason why, if the pitch were included, the formula should not inelude also the area and shape of the blades, whereby it would become considerably complicated. The volumetric formula was almost of more value for finding the dimensions of a fan than it was as a measure of efficiency; and it had a great advantage he considered in not being governed by a doubtful quantity like the pitch.

The fact that the formula constructed by Mr. Wingfield from Mr. R. E. Froude's experiments showed that when the pitch was fine the screws should have negative slip (page 476) was the natural consequence of Mr. Froude's model experiments having been made 
with blades having rounded backs: so that, when the piteh was measured from the front face, negative slip might be expected to oceur through not taking the rounded backs into account; and those experiments corroborated his own.

The statement in page 465 that helical blades did not possess advantages over non-helical (page 486) was meant to apply only to the particular experiments in pages $464-5$, in which the helical blades had not rendered the velocity of discharge more uniform than it was with flat blades. Mr. Wingfield's comparison of pitch (page 486) was derived from only one form of flat blade, for which the pitoh had been taken from the angle at the tips of the flat blades; but the mean pitch of the flat blade came out less than that of the helical: so that it seemed hardly correct to say that the pitch of the flat blade was 37 per cent. greater than of the helical.

With Mr. Mudd's important remark as to forced and induced draught (page 487) he entirely concurred. It was true that the particular experiments which he had been making showed that for induced draught these propeller ventilating fans were more efficient than for forced draught. But as to induced draught being always more efficient than forced draught, he had not made any such remark, because he had not carried out a sufficient number of experiments to justify such an opinion.

The Prfistontr considered Mr. Walker's original and supplementary papers had proved both valuable and interesting; and they had raised a discussion which was also characterised by the same qualities. He was sure therefore that the members would accord to him a hearty vote of thanks.

Dr.J.S. HaLdANe, Oxford, wrote that, as a member of the Board of Trade Committee on the Ventilation of Metropolitan Tunnels, he had recently had to consider carefully the effects capable of being produced by fans or other ventilating appliances, when used to extrast large volumes of air against slight resistances. In short 
(Dr. J. S. Haldane.)

lengths of tunnel, such as those on the Metropolitan Railway, the resistance in the tunnel itself, when about 240,000 cubic feet of air per minute were being extracted, would be only about 0.02 inch of water, or $0.1 \mathrm{lb}$. per square foot (see Report of the Committee, appendix 1). This was only about $1-100$ th of the resistance ordinarily met with in the ventilation of mines, and in similar cases where a large volume of air had to be drawn through comparatively long and narrow passages with irregular walls ; consequently the problem of tunnel ventilation was in many respects different from that of mine ventilation. In particular the work expended in simply passing the air through the fan itself and through its inlet and outlet passages came to be of the utmost importance. Thus, to take an example, he bad calculated that, in one of the centrifugal fans referred to before the Committee, only about 1-10,000th part of the horse-power expended in driving the fan was applied in moving the air in the tunnel itself, the remainder of the power being absorbed in simply passing the air through the fan and the ducts immediately connected with it.

It appeared to him that the present paper had furnished now and valuable data with respect to the economical application of fans to the extraction of large volumes of air against low resistances, as in the ventilation of comparatirely short tunnels and in many similar. cases. The experimental data hitherto published as to the action of fans seemed all to have been obtained with reference to resistances of an inch or more of water. The action of fans or other appliances working against low resistances had been strangely neglected or. aroided by engineers. It was a great step forward, he considered, to have now on record definite quantitative data, which showed clearly that the internal resistance of a fan could be reduced almost indefinitely without impairing its efficiency: so that, by means of properly designed and properly applied propeller fans, enormous volumes of air could be extracted against low resistances with a trifling expenditure of work. He should like to ask the author whether he thought it would be worth while to carry out some further experiments asito the effect which would be produced on the mechanical efficiency of his experimental fan by making the inlet or 
outlet of the tube funnel-shaped. Judging from the experiments described by Peclet (Traité de la Chaleur, vol. 1, book 2, chap. 4), the shape of the inlet and outlet would have a great influence on the work absorbed in passing the air through the tube. If tho waste of energy due to the abrupt inlet or outlet were avoided, it would be possible to make a fairer comparison between the mechanical efficiencies of propeller and centrifugal fans.

Mr. R. Edmund Froude wrote that he thought the author was perfectly right about the rounding of the backs of the blades conducing to apparent negative slip by increasing the effective pitch, for that was what it came to. At the Admiralty Experiment Works, Gosport, experiments on model screw-propellers in water had shown that, in a blade of parallel thickness, hollowing the face of the blade gave an effective pitch greater than the mean pitch; and that rounding the back, while the face remained a true helix, had the same effect. The model screws used in the experiments whence Mr. Barnaby's tables had been derived were of ordinary type, with true helical face and round back; the thickness to scale was much the same as in full-size bronze propellers. The point however was so much a side issue in the present paper, that he did not think it worth while to remark on it further in this connection.

Mr. Hiram S. Maxim wrote that, before commencing his flying-machine experiments at Baldwyn's Park, he had endeavoured to obtain some information in regard to the action of screw propellers working in the air. He went to Paris and saw the apparatus employed by the French government for testing the effieiency of screw propellers; but the propellers tested were so badly made that the tests were of no value. An English experimenter who professed to have made a life-long study of the subject had assured him that the screw propeller would be found inefficient and wasteful of power, because it had a strong fan-blower action, drawing air in at the centre and discharging it with great force at the circumference. Most of the data and formulæ he had been able to meet with were so confusing and contradictory as to be of no value 
(Mr. Hiram S. Maxin.)

whatsoever. In computing the thrust of a screw, some experimenters were of opinion that the projected area of the blades should alone be considered; and that the thrust wonld be equal to a wind blowing against a normal plane of equal area to the blades at a velocity equal to the slip. Others thought the whole screw dise would have to be considered : that is, that the thrust would be equal to a wind blowing against a normal plane equal to the area of the whole disc at the velocity of the slip. The total projected area of the blades of the two screws in his large flying machine was 94 square feet, and the joint area of the two screw discs was 500 square feet. By the first mode of calculating therefore, the screw thrust of the machine, when running at 40 miles an hour with a slip of 18 miles an hour, would have been, according to the well known formula, $18^{2} \times 0.005 \times 94=$ 152 lbs. If however, by the second method, the whole screw dise were considered, it would have been $18^{2} \times 0.005 \times 500=810 \mathrm{lbs}$. When the machine was run over the track at this rate of 40 miles an hour, the thrust was found to be rather more than $2,000 \mathrm{lbs}$. When the machine was secured to the track and the screws revolved at such a speed that the pitch in feet multiplied by the turns per minute was equal to 68 miles an hour, the thrust was found to be $2,164 \mathrm{lbs}$. In this case the motion was of course all slip; and after the screws had made a few turns, they had established a steady air-current, and the power exerted by the engines was simply spent in maintaining this current; and it was interesting to note that, if computed from the projected area of the blades by the same formula, the thrust would now be $68^{2} \times 0.005 \times 94=2,173$ lbs., which was almost exactly the observed thrust. Hence it would appear that, when the machine was stationary and all the power was consumed in slip, only the projected area of the screw blades should be considered. But whenever the machine was allowed to advance and to encounter new air, the inertia of which had not been disturbed, he had found that the efficiency increased in geometrical progression. The exact rate of this progression for all speeds he had not yet ascertained. His experiments however had shown that, with a speed of 40 miles an hour and a slip of 18 miles an hour, a well made screw-propeller was thirteen times as efficient as had been supposed by early experimenters. 
Mr. BasIL H. Jor wrote, in reference to the apparently greater power of the induced side of a current of air than of the discharge side, that some small experiments with which he had been connected would seem almost to point to the opposite conclusion : although he quite appreciated the fact that the two cases were not parallel, because the source of power was different in each. In his own experiments the current of air was obtained by means of a jet of water from an ordinary house supply, which by passing through a special shape of rose or spray nozzle was spread out so as to form a sort of water piston that completely flled the bore of a vertical tube of about 5 inches diameter. The effect of this piston was to induce a powerful current of air down the tube, which affected the flame of a candle held at a distance of about 8 feet from the orifice of a horizontal discharge bend at bottom; but when the candle was held in front of the suction inlet at top, the flame was not affected at a distance of more than about $2 \frac{1}{2}$ feet, at which distance it would be blown out at the discharge outlet.

Mr. WaLker quite agreed with the remarks of Dr. Haldane (pages 493-5) as to the small amount of power necessary for the ventilation of tunnels, in comparison with that required for mines. As suggested, he intended carrying out some experiments with funnel-shaped inlet and outlet. Where expansion or contraction of air took place, as in centrifugal fans, a funnel-shaped outlet, allowing of a more uniform expansion of the air from the fan down to the pressure of the atmosphere, would tend he thought to increase the mechanical efficiency. An air propeller generally worked at atmospheric pressure, and the air was sucked in from all points behind the fan at a nearly uniform rate, and in the form of an imaginary cone. Having thus far measured the discharge when it took place through a cylindrical tube, he purposed replacing the cylindrical by a funnel-shaped tube of equal length, in order to find out what effect would thereby be produced upon the mechanical efficiency.

The view that the rounding of the backs of the blades conduced to apparent negative slip was corroborated by Mr. Froude's remarks (page 495). 
(Ur. Walker.)

Referring to Mr. Maxim's experiments (pages 495-6), he had himself arrived theoretically at the following formulo:--thrust = (revolutions $R$ per minute) $)^{2} \times$ (diameter) $^{4} \times$ constant $C$; horsepower to drive propeller $=R^{3} \times$ (diameter $)^{5} \times C$; also for the same propeller, thrust $=R^{2} C$, and horse-power $=R^{3} C$. His own experiments showed that the thrust varied actually as the square of the revolutions per minute, and nearly as the fourth porrer of the diameter; in these particular experiments the propellers were not precisely similar, which might account for the thrust not varying precisely as the fourth power of the diameter.

In Mr. Basil H. Joy's experiment the air would be sucked into the inlet from all points behind in a uniform manner and in the shape of an imaginary cone, which would account for the small effect on the candle at $2 \frac{1}{2}$ feet distance from the inlet. At the outlet the effect was quite different, because the air would be discharged straight forwards in a cylindrical column, and would retain its velocity for some considerable distance. Had the candle been placed quite close to the inlet and to the outlet, the wind would have had the same effect on the flame in each position, because the same quantity of air was entering at the inlet that was leaving at the outlet. If any conclusion could be drawn from the experiment, it would be in favour of induced draught, by showing that the feed could spread itself all round over a larger area, thereby producing a smaller velocity of current at a shorter distance from the inlet; and this smaller velocity for the same amoint of feed was naturally conaucive to increased efficiency, and the principle was somewhat similar to that of the expanding or conical chimney often employed on the outlet of centrifugal ventilating fans. 
PROPELLER VENTILATING FANS.

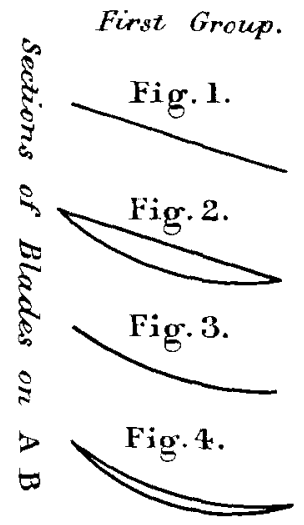

Second Group.
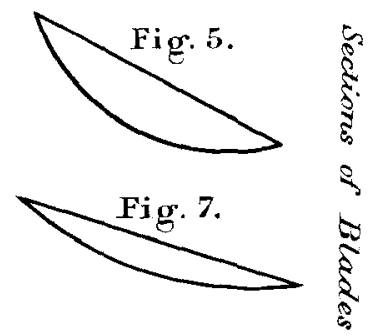

Third Group.

Plale 79. Fourth Group.
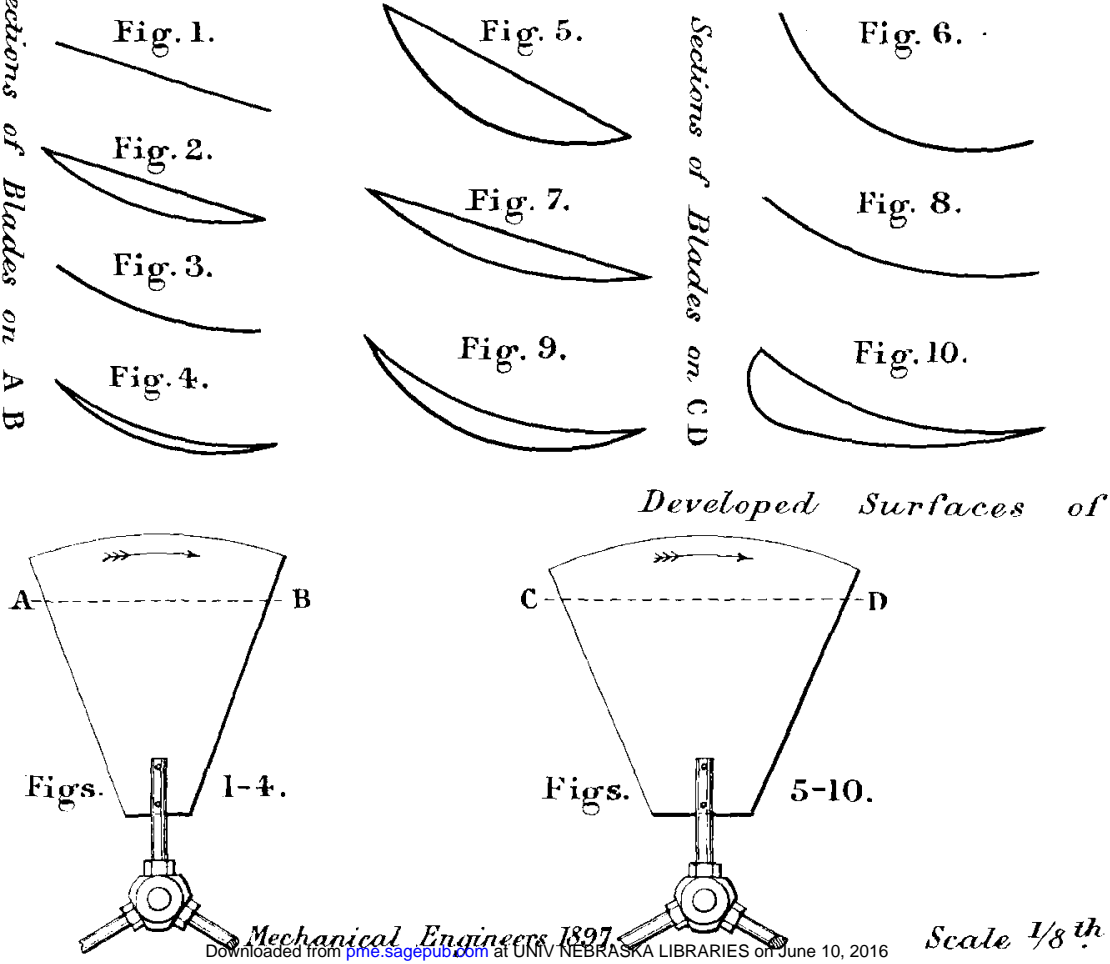

5
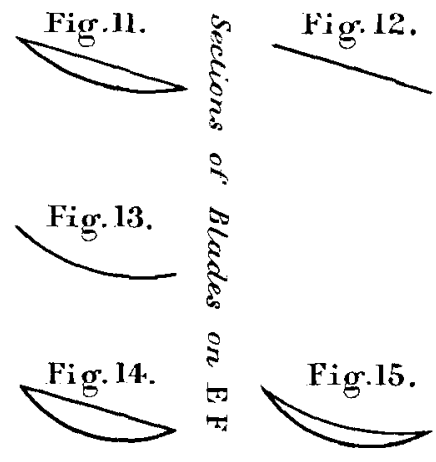

\section{filades.}

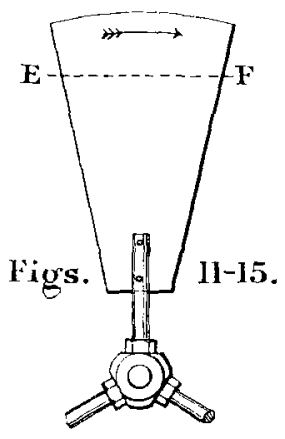

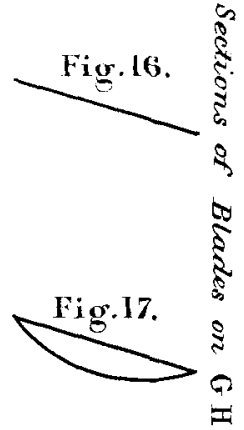

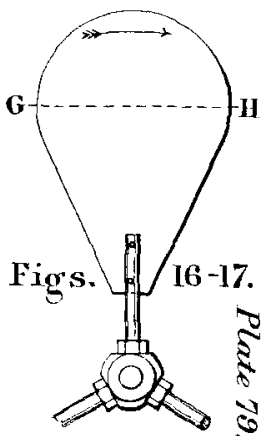




\section{PROPELLER VENTILATING FANS.}

$$
\text { Fan-Testirg Apparatus. }
$$

Electric Motor and Fin with three blades.

Fig. 18. Plan.

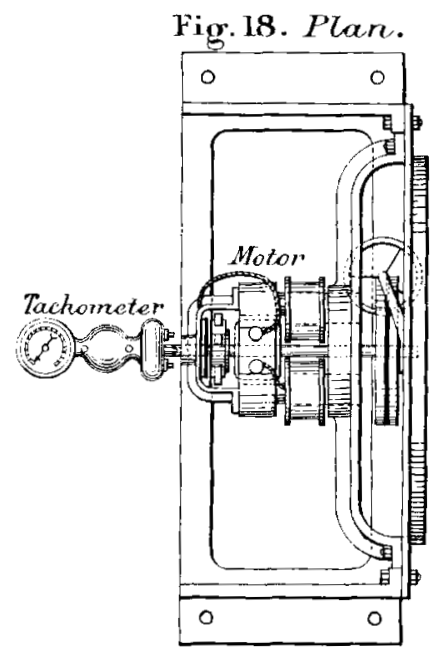

Fig. 19. End Elevalion.

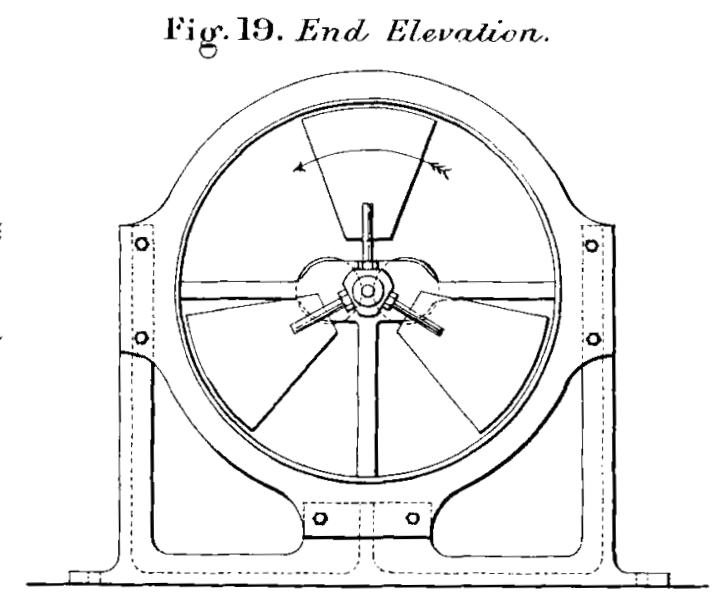

Inches $10 \quad 5 \quad 0$
Bratie Dynamomeler.

Fig. 20. End Elevation.

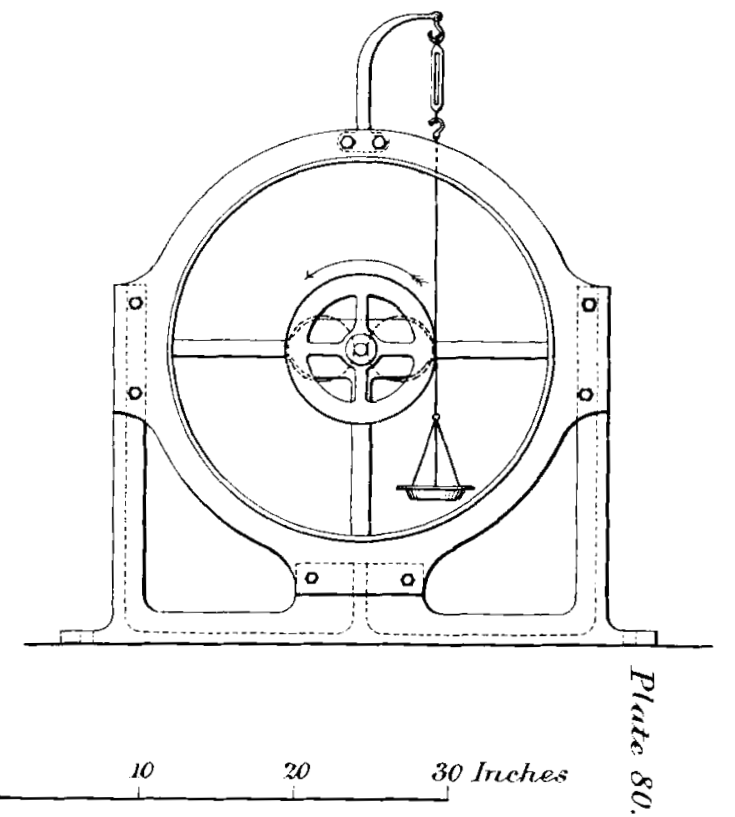




\section{PROPELLER VENTILATING FANS.}

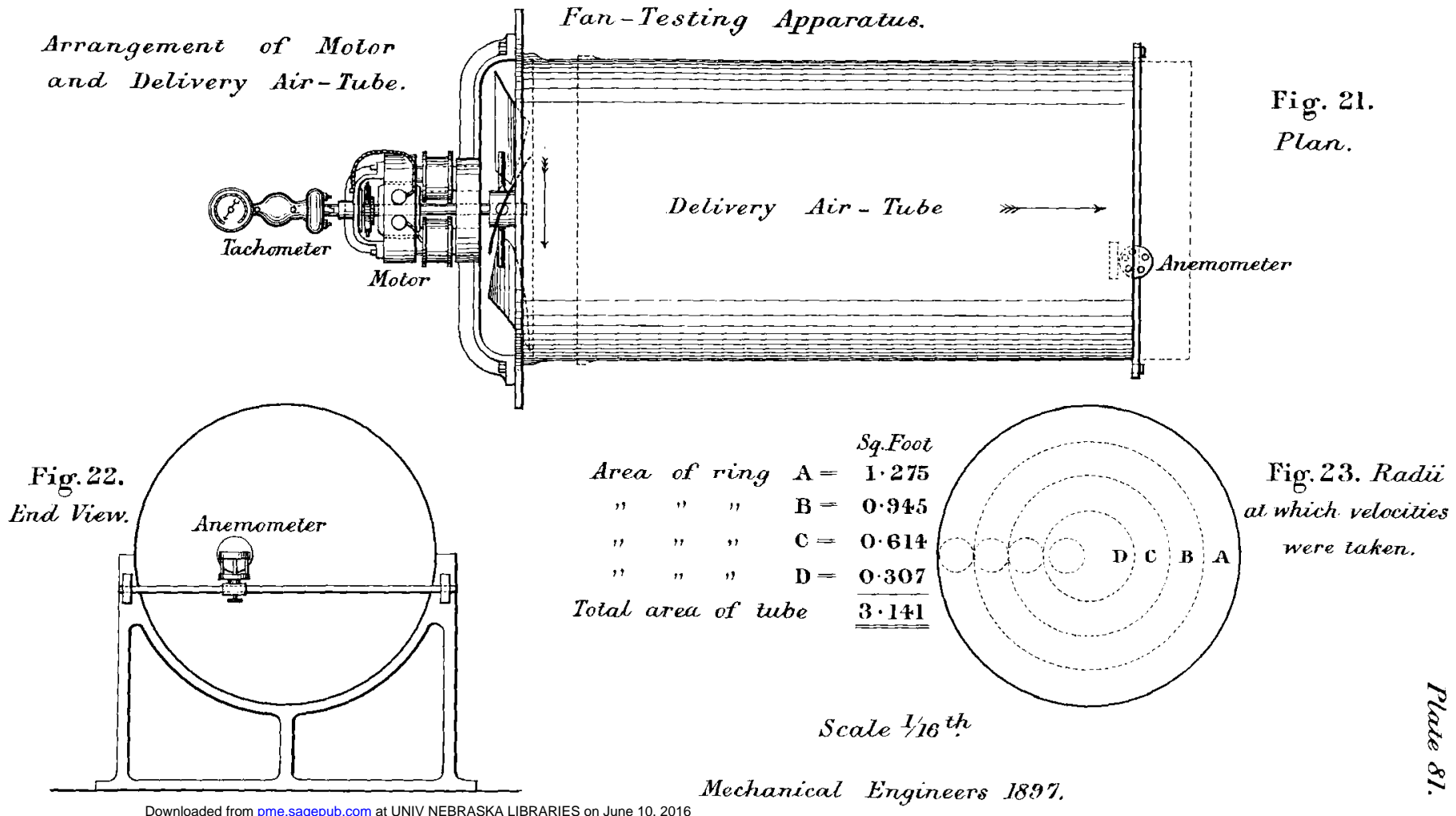


PROPELLER VENTILATING FANS. Plate $8:$.

Ampoères

Series Electric Motor.

3.0

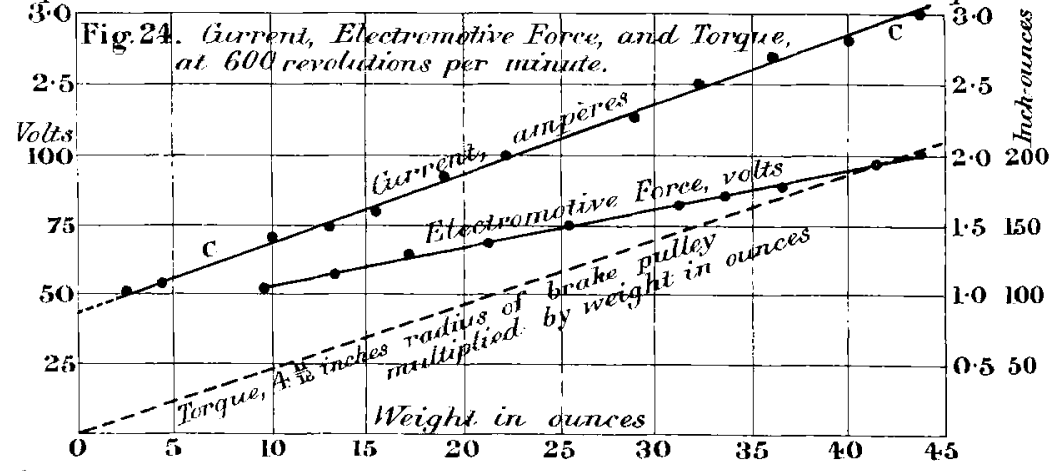

Amperes

Ampères
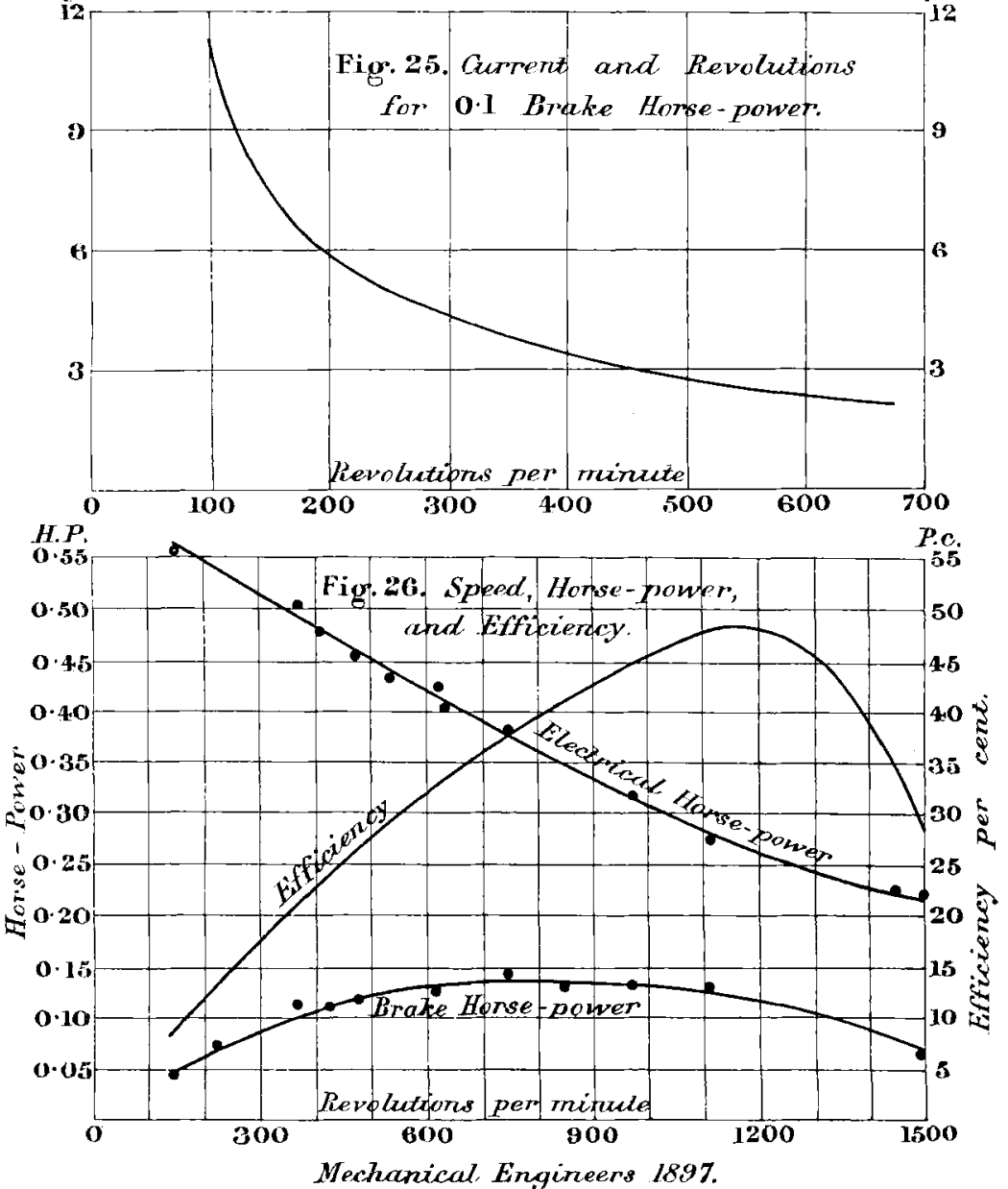

Downloaded from pme.sagepub.com at UNIV NEBRASKA LIBRARIES on June 10, 2016 
PROPELLER VENTILATING FANS. Plate 83.

Gubic

Feet.

Fans 1-2-3-4, angle of bludes 17.

7000

Fan 9, angle of blades $27^{\circ}$.

Gabic

Feet

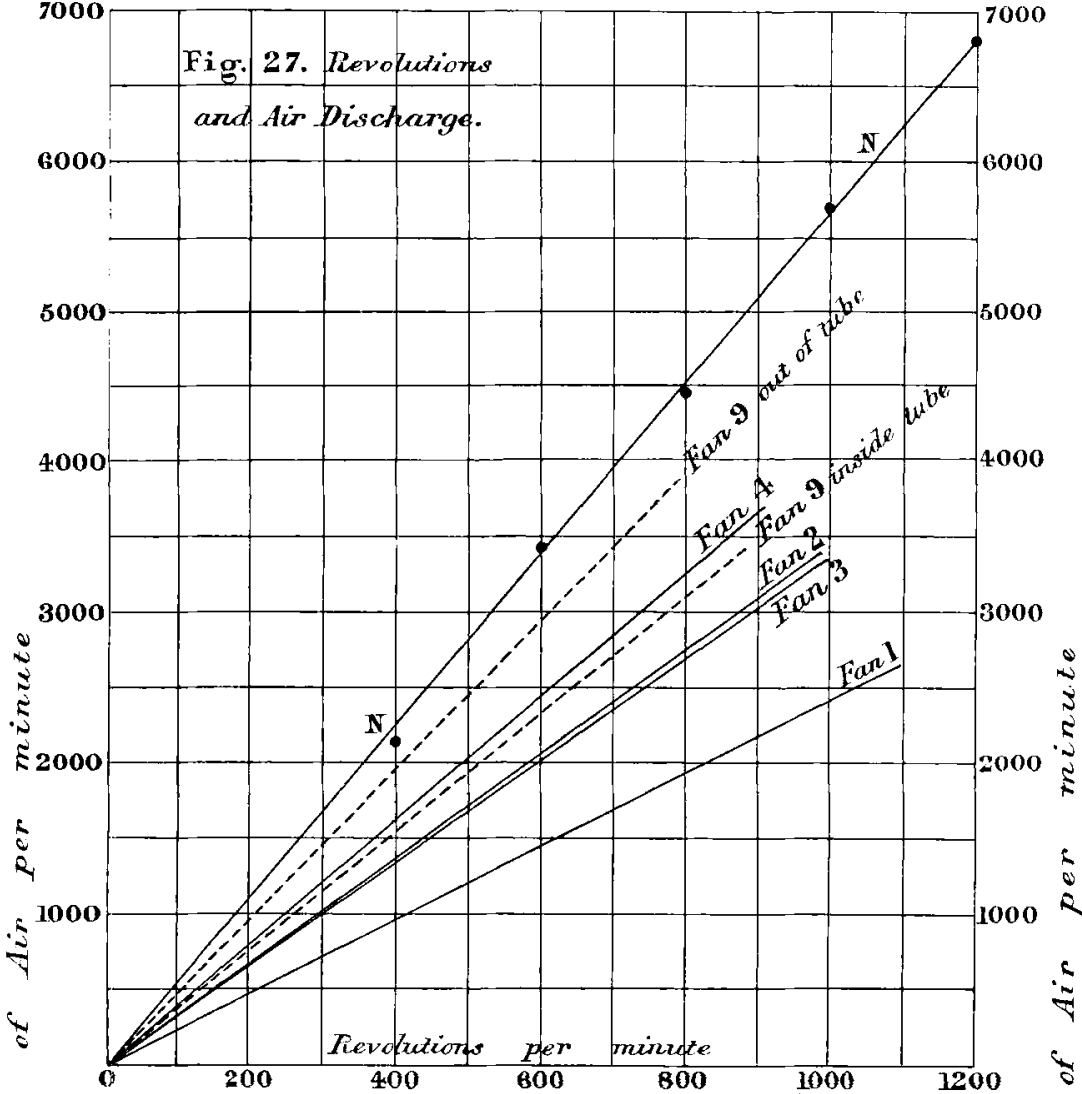

舟

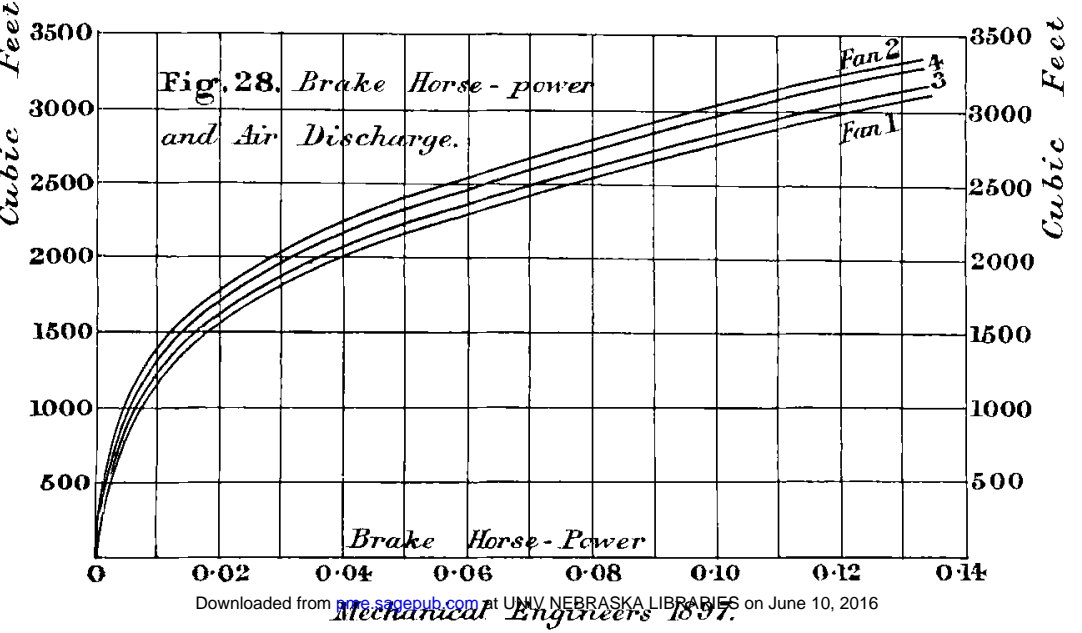


PROPELLER VENTILATING FANS. Plate 84 .

Fig. 29. Characteristic Cirves of Fan 17.

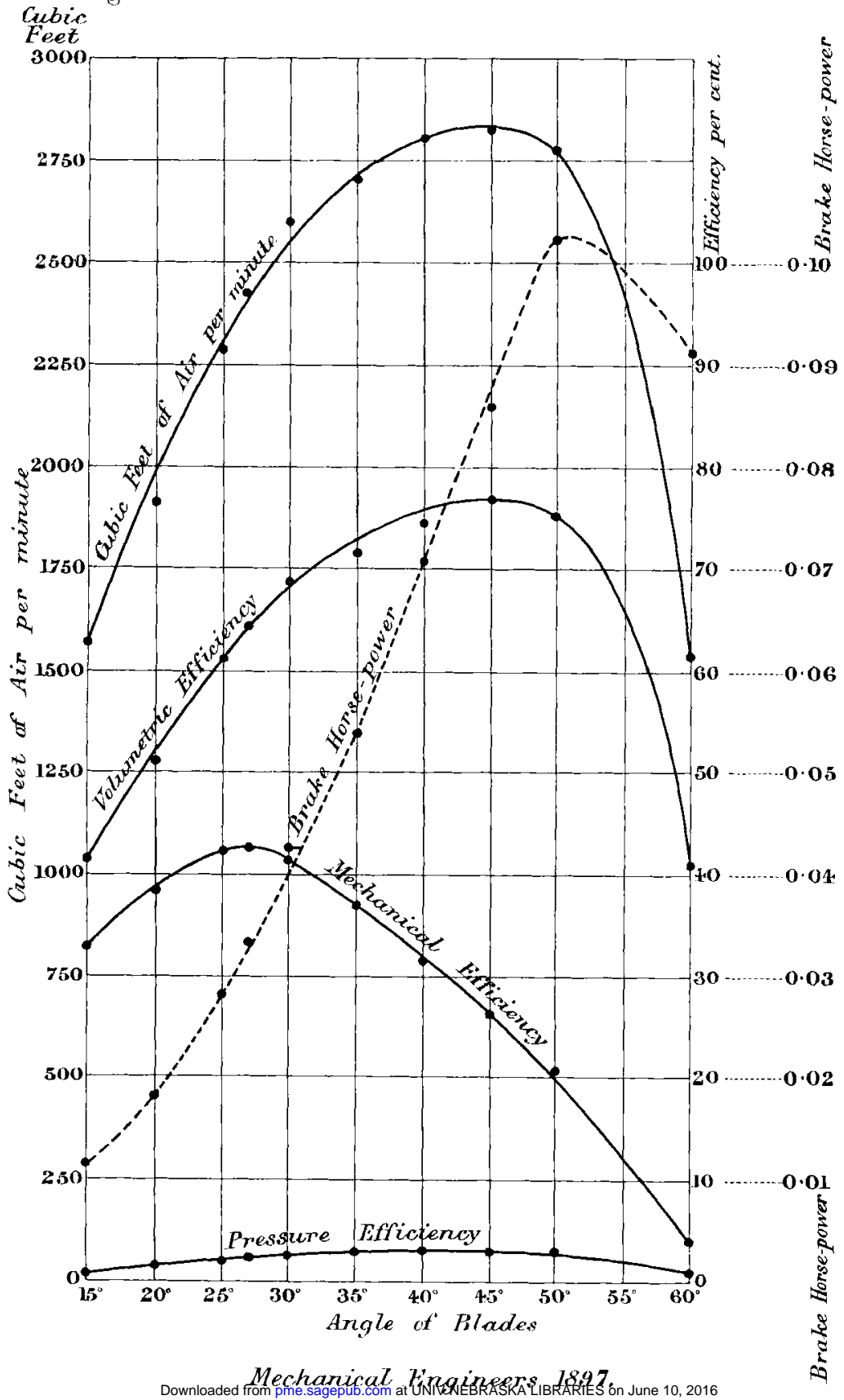


PROPELLER VENTILATING FANS. Plate 85.

Fans 16 and 17.

Friclion of Motor included.
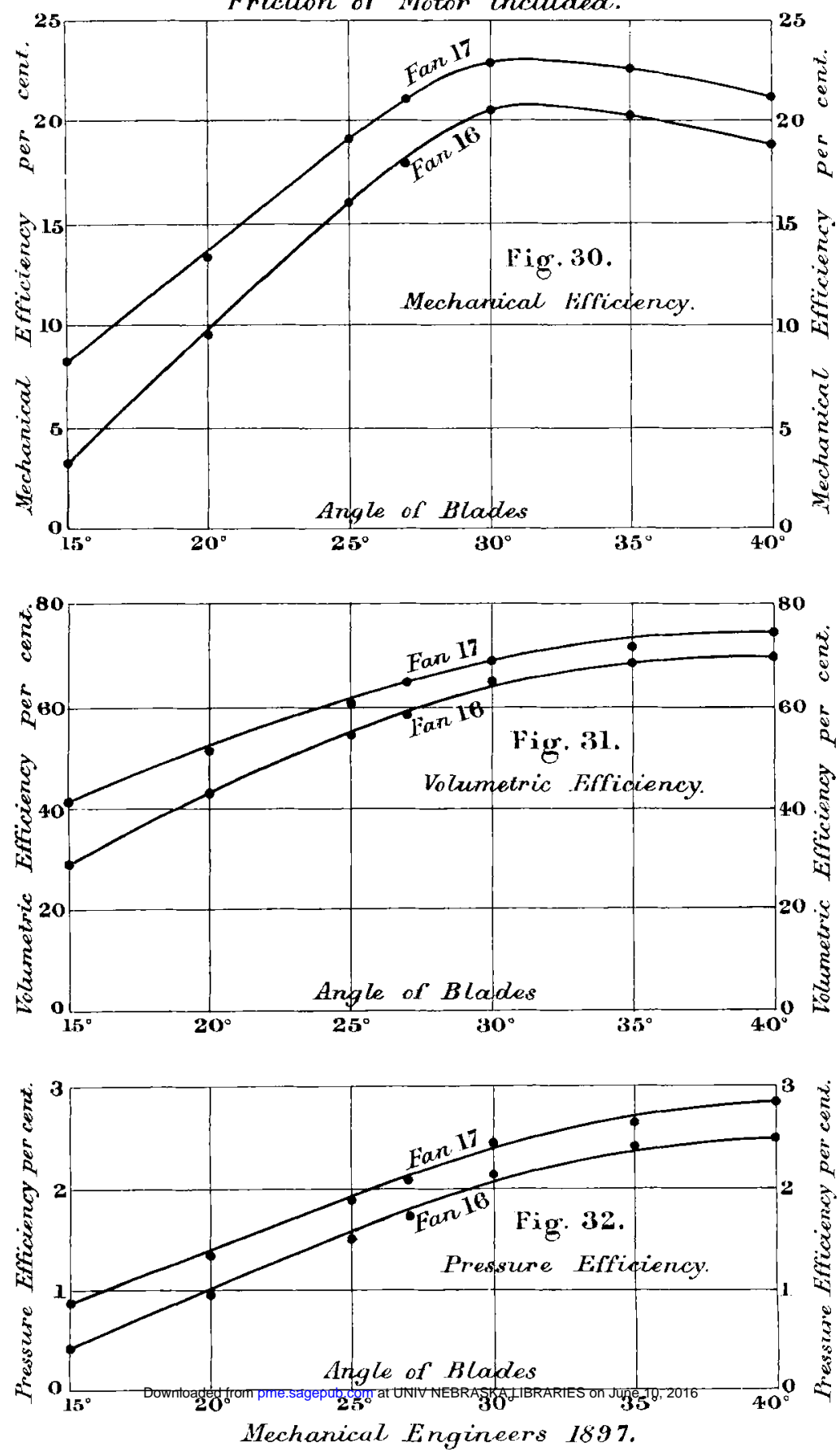

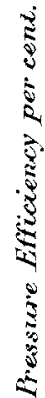

Mechanical Engineers 1897. 


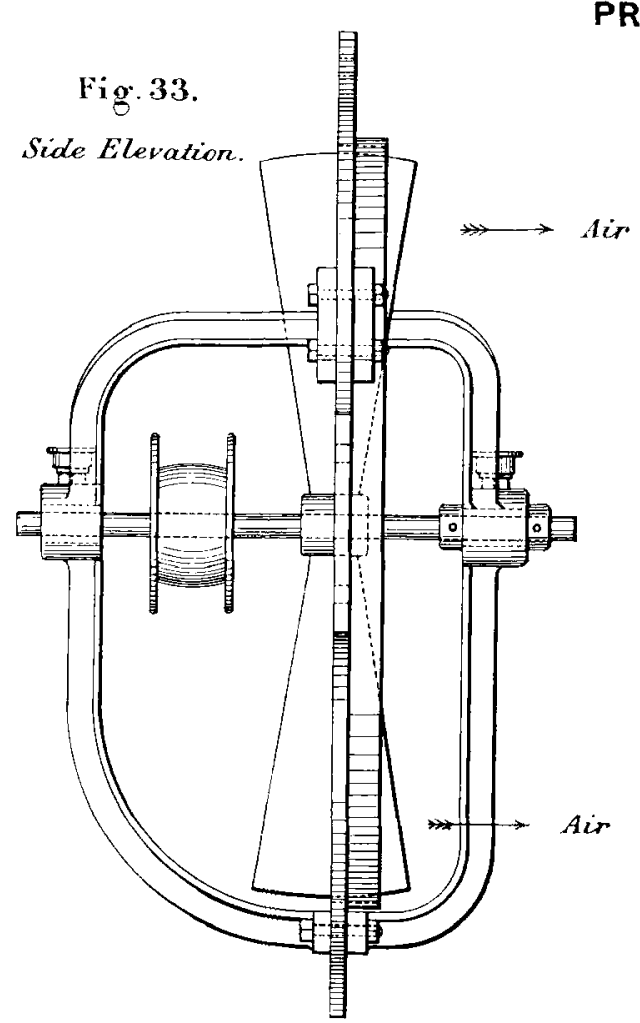

PROPELLER VENTILATING FANS.

Mechanical Eingines 1897 o

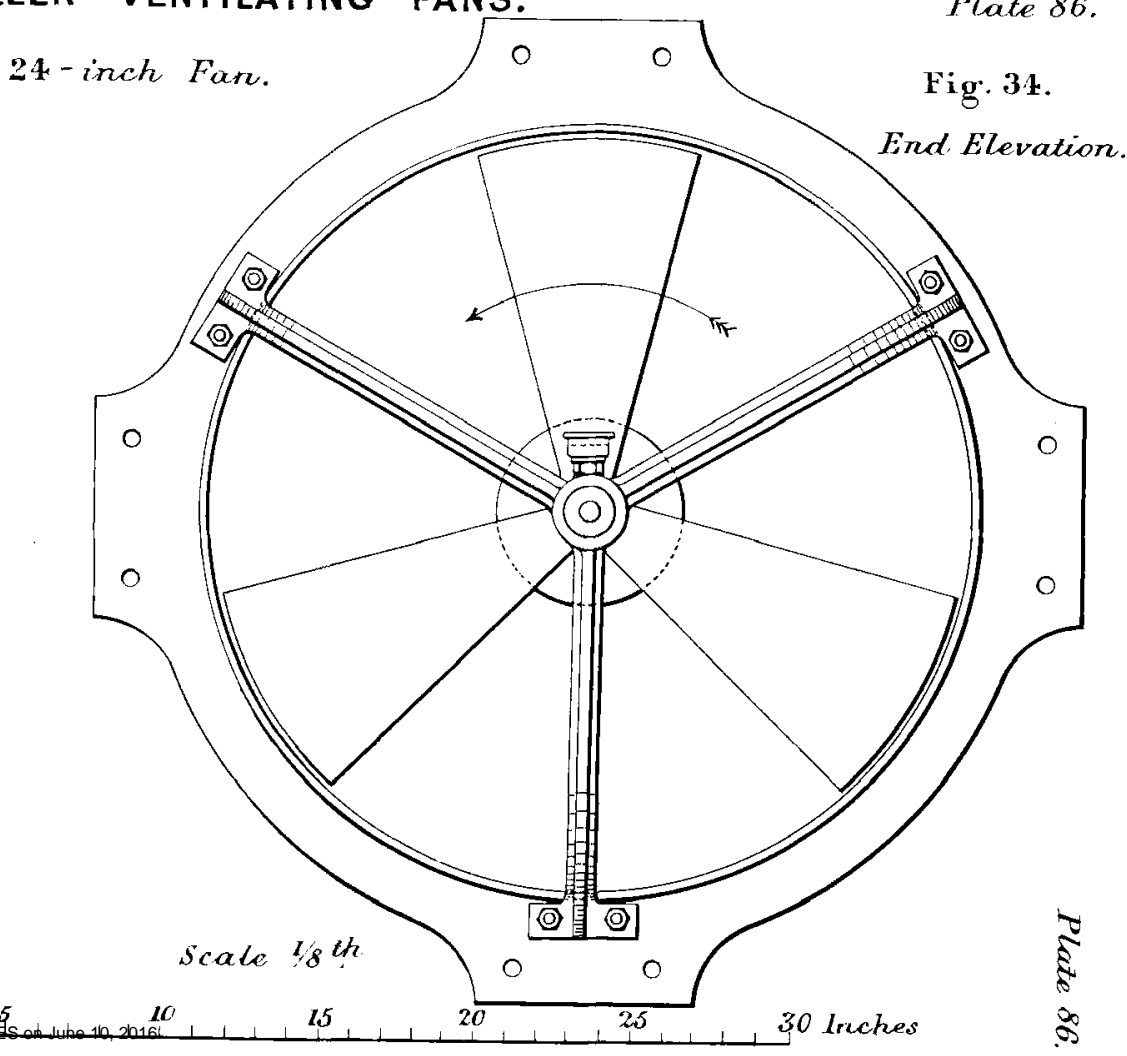




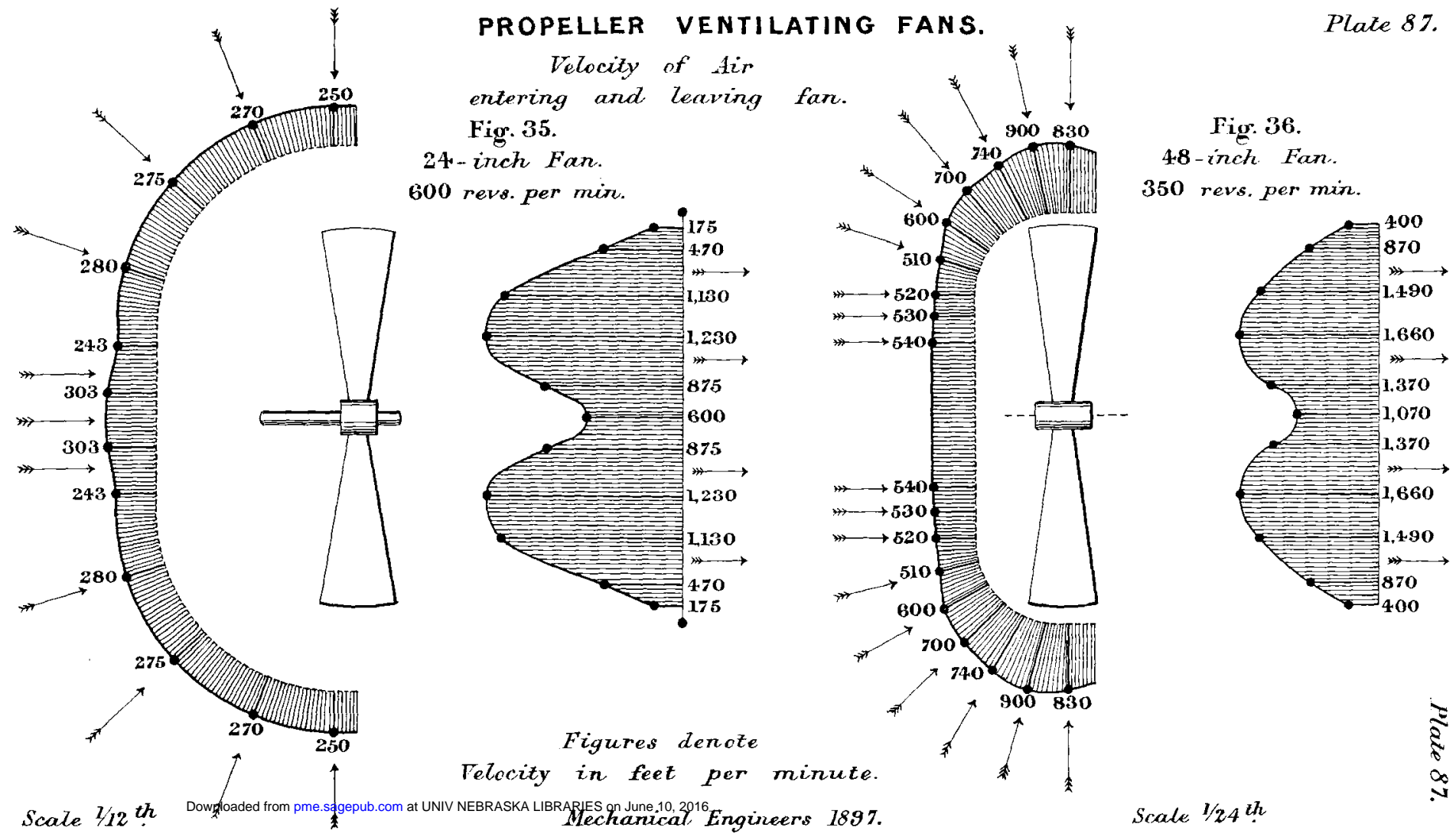


PROPELLER VENTILATING FANS.

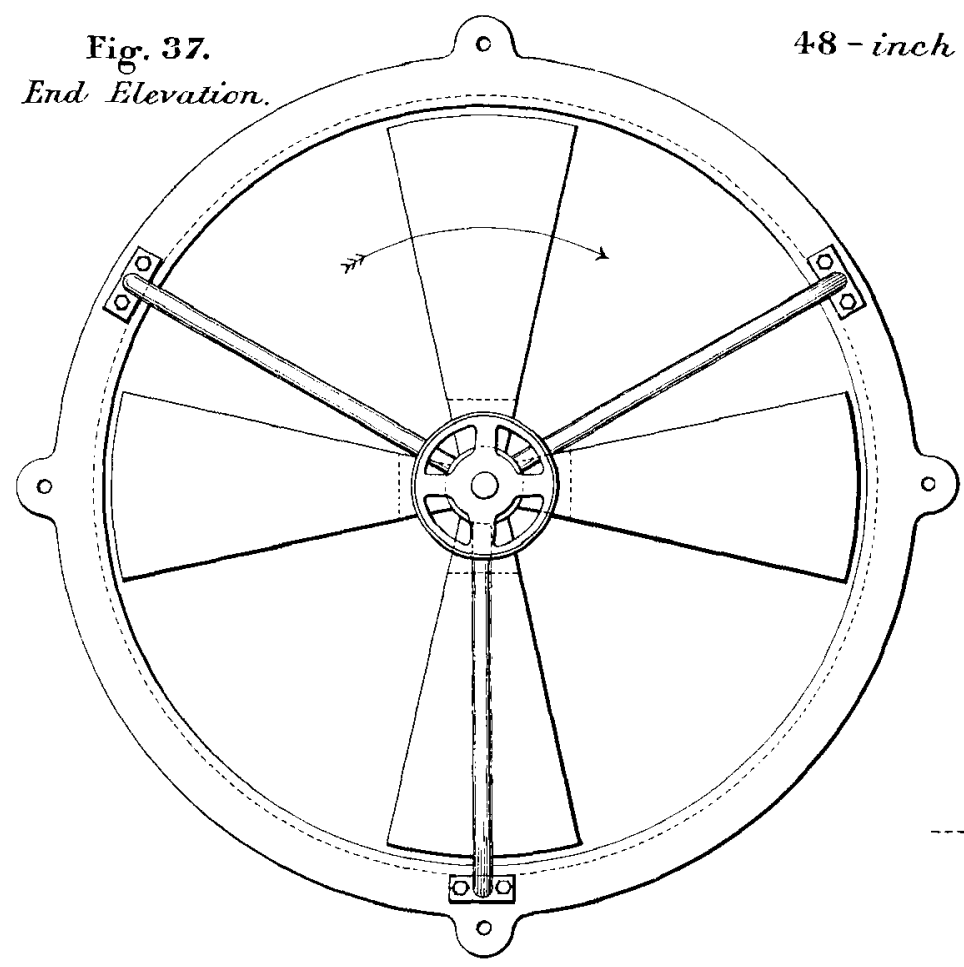

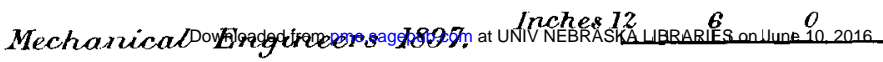

Fig. 39.

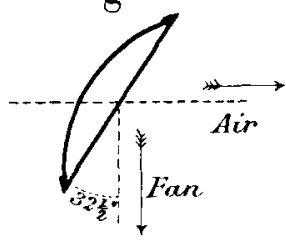

Scale $1 / 16^{\text {th }}$

3

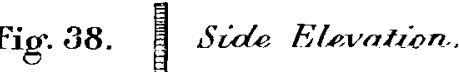

Air 


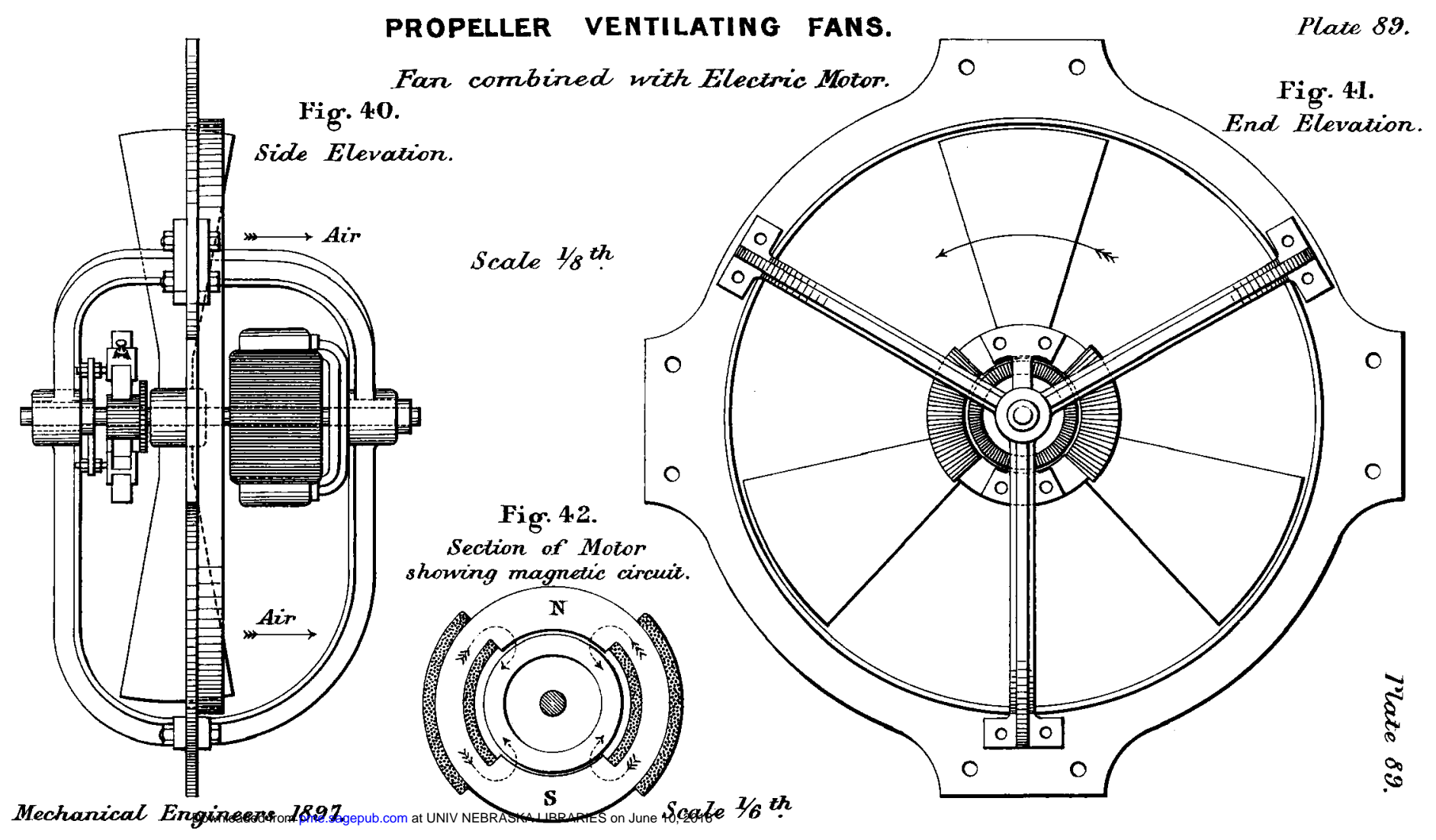


PROPELLER VENTILATING FANS.
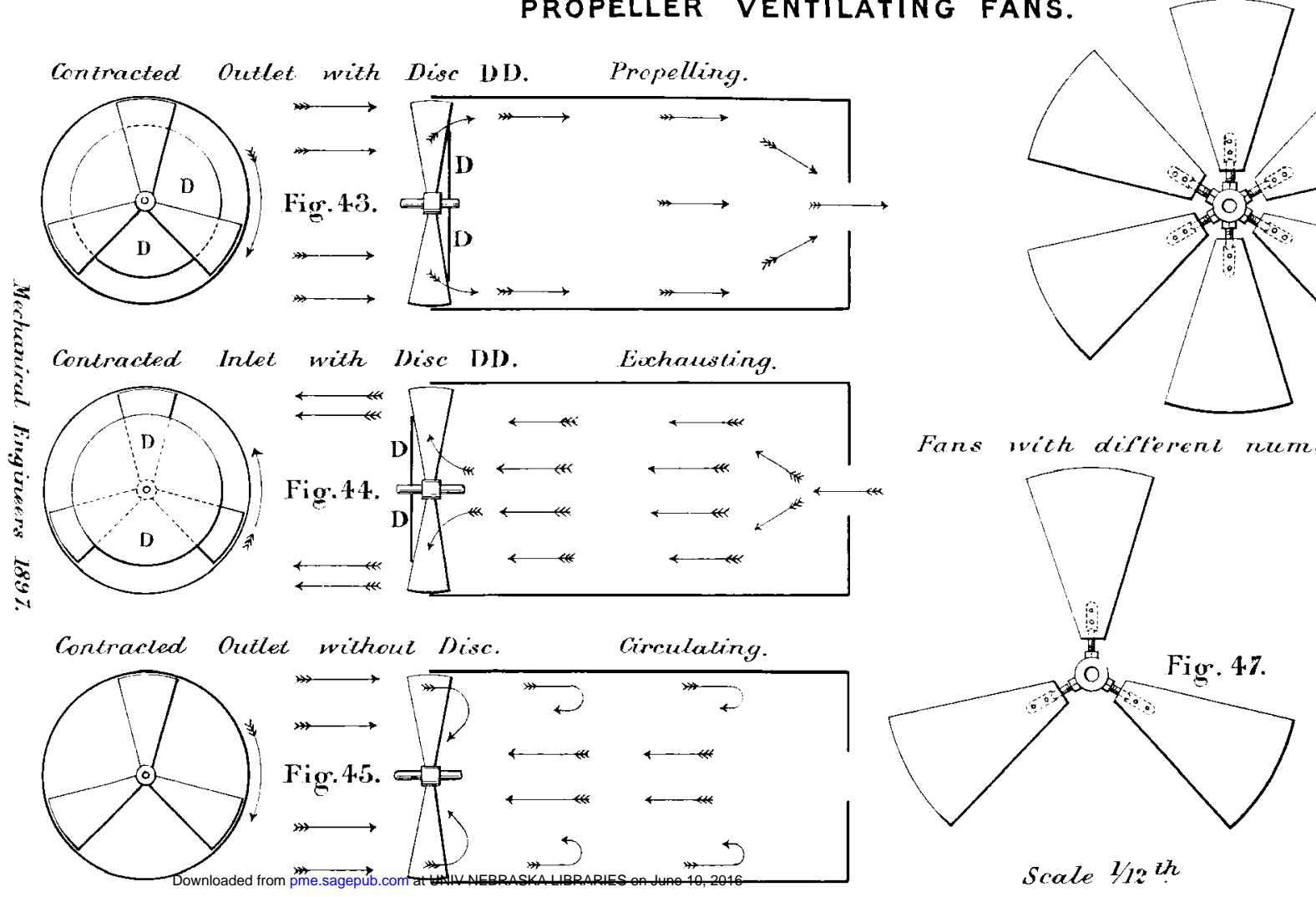

Plate 90.

Fig. 46.

Fans with defterent numbers of Blades.

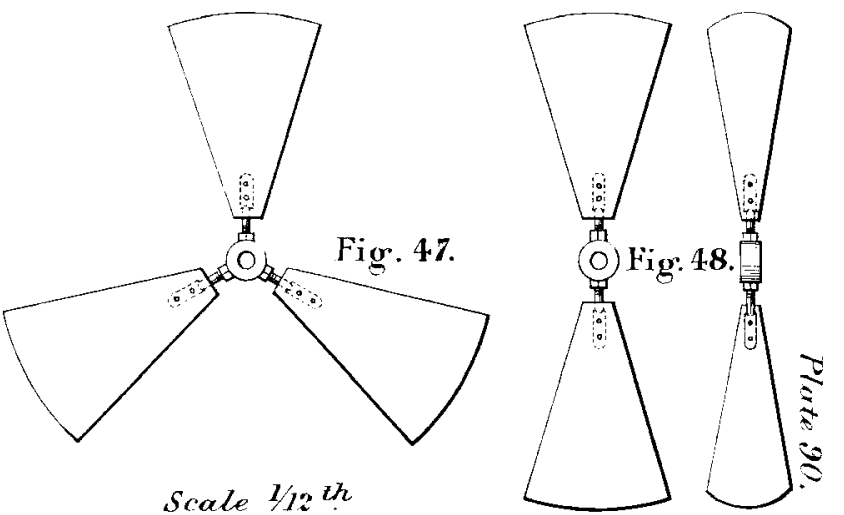




\section{PROPELLER VENTILATING FANS.}

Place 9l.

Fig. 49. Pitch 3 foet.

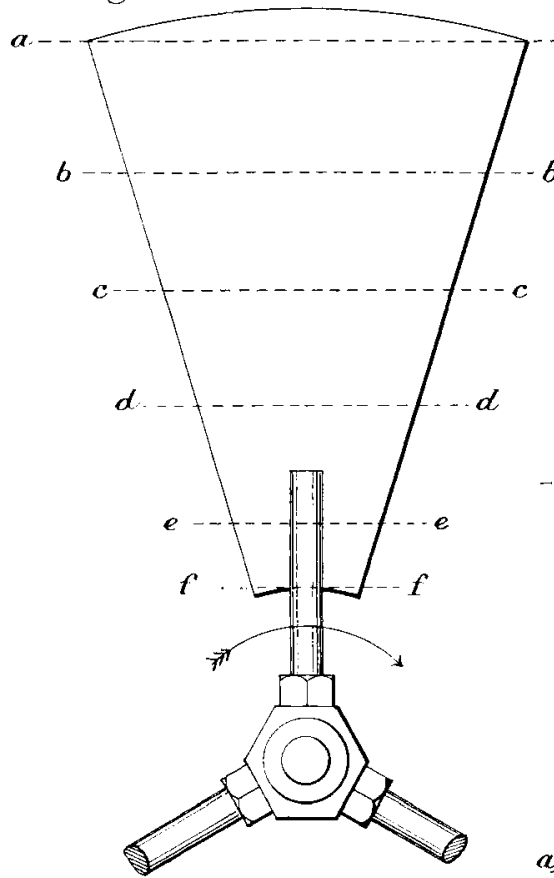

Mechanical Engineers 1897.

Downloăded from pme.sagepub.com at UNIV NEBRASKA LIBRARIES on June 10, 2016
Fig. 52. Cross Seciions of Blades.

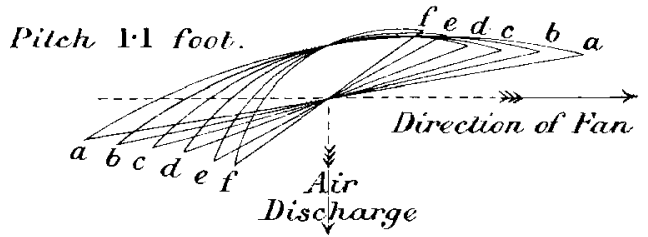

Plans showing Blade Argles at different radii.

Fig.50. Fig. 51 .

Pitch 3 reet.

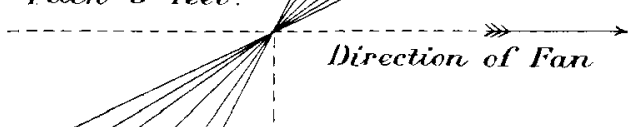

a b c der

Air

Discharge
Pitch $1 \cdot 1$ foot.

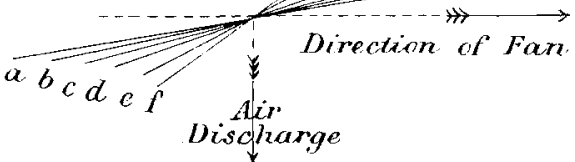

Fig. 53.

$$
\text { Circumferences }
$$


PROPELLER VENTILATING FANS.

Plute 92.

\section{Helical Blades.}

Fig. 5t. Ascial Velocizy of Air. 24-inch Fan Fig.55. Rotary Velocity of Air.
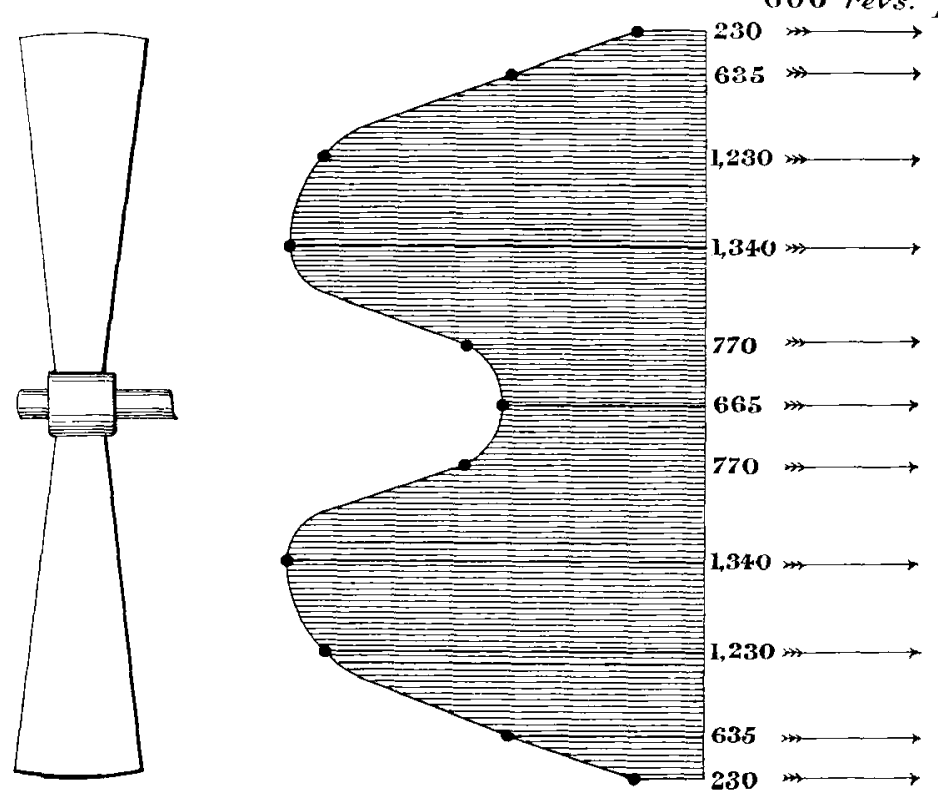

Fügures denote

Mechanical Engincers 1897.

Ielocity in feet per minute.

Downloaded from pme.sagepub.com at UNIV NEBRASKA LIBRARIES on June 10, 2016

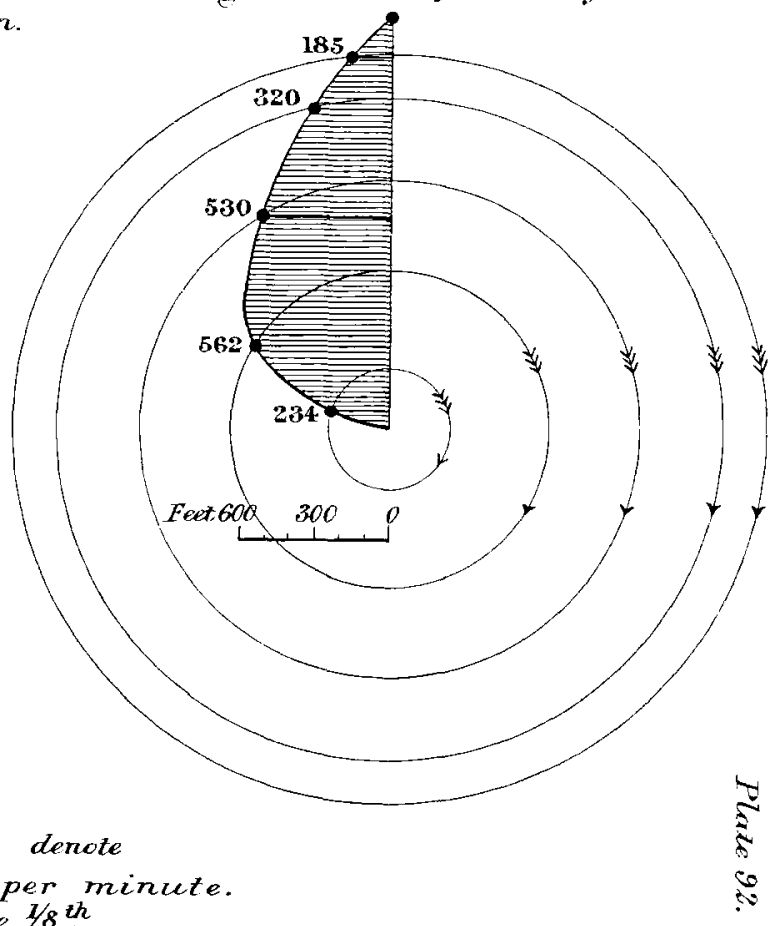




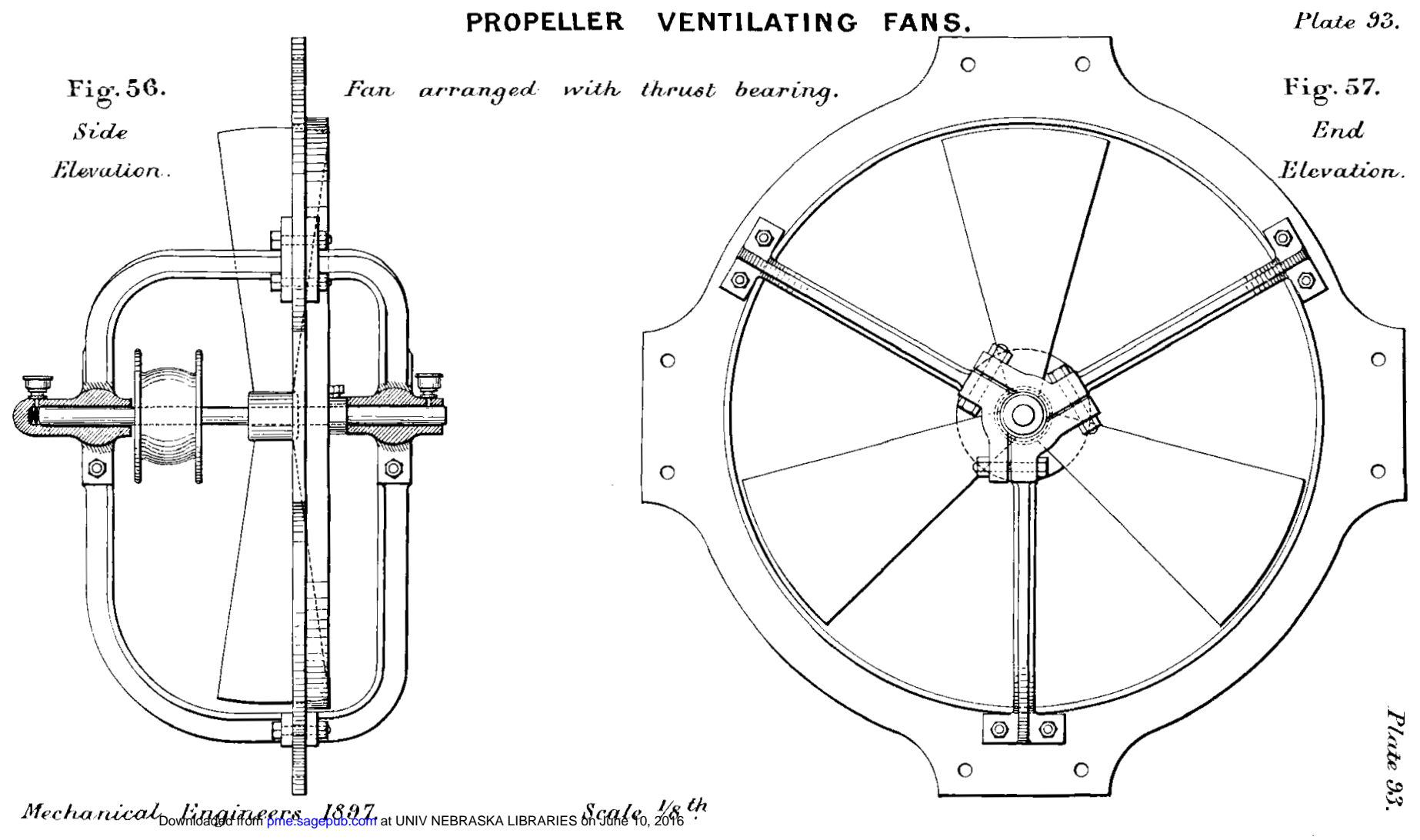


PROPELLER VENTILATING FANS, Plate 94.
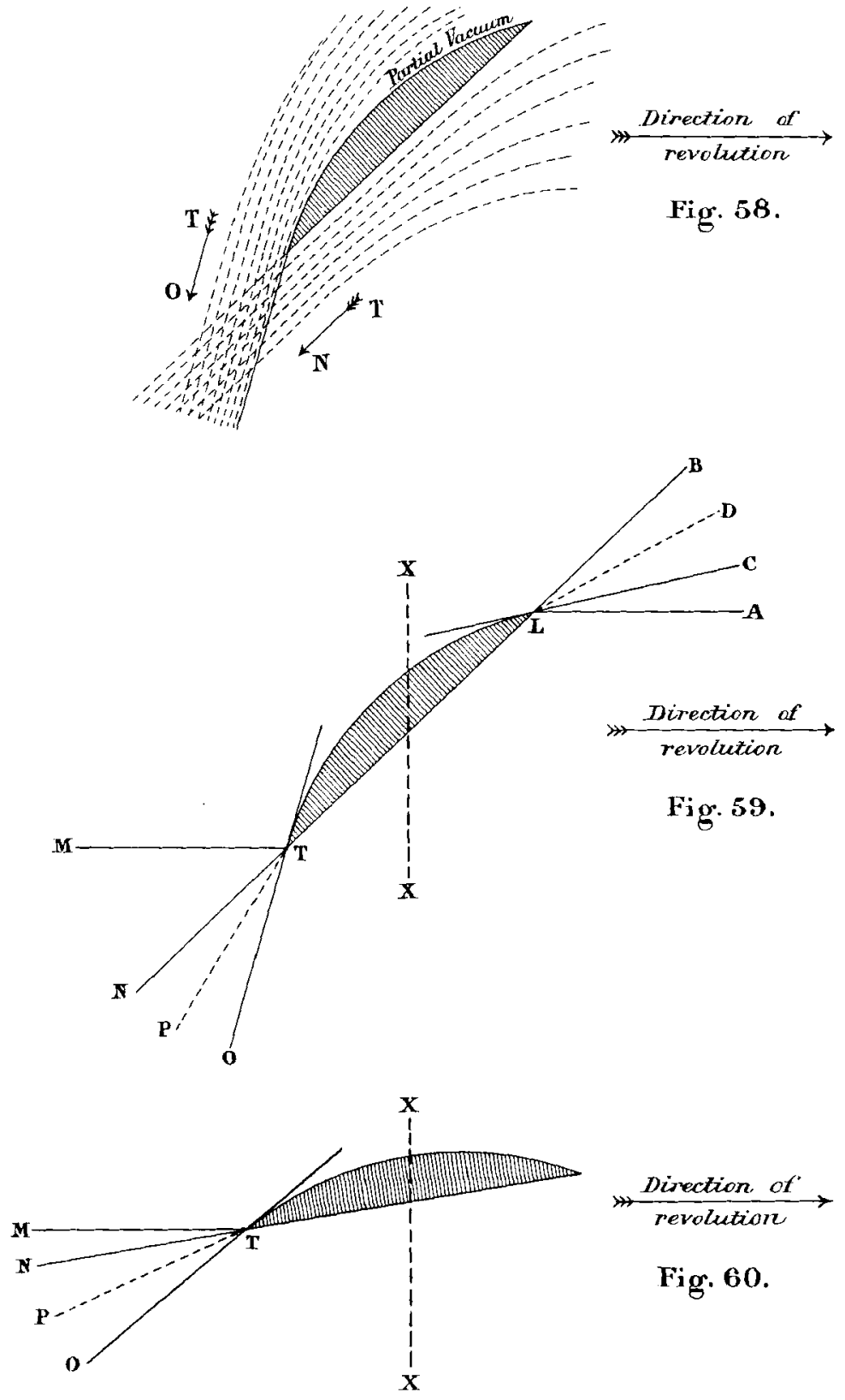

Mechanical Fingineers 1897

Downloaded from pme.sagepub.com at UNIV NEBRASKA LIBRARIES on June 10, 2016 